\title{
ChemComm
}

Check for updates

Cite this: Chem. Commun., 2021, 57,11131

Received 3rd August 2021, Accepted 21st September 2021

DOI: $10.1039 / \mathrm{d} 1 \mathrm{cc} 04237 \mathrm{~h}$

rsc.li/chemcomm

\section{Bio-instructive materials on-demand - combinatorial chemistry of peptoids, foldamers, and beyond}

\author{
Claudine Nicole Herlan, (D) ${ }^{a}$ Dominik Feser, (ID ${ }^{\mathrm{b}}$ Ute Schepers (D) $*^{\mathrm{bc}}$ and \\ Stefan Bräse (iD *ac
}

\begin{abstract}
Combinatorial chemistry allows for the rapid synthesis of large compound libraries for high throughput screenings in biology, medicinal chemistry, or materials science. Especially compounds from a highly modular design are interesting for the proper investigation of structure-to-activity relationships. Permutations of building blocks result in many similar but unique compounds. The influence of certain structural features on the entire structure can then be monitored and serve as a starting point for the rational design of potent molecules for various applications. Peptoids, a highly diverse class of bioinspired oligomers, suit perfectly for combinatorial chemistry. Their straightforward synthesis on a solid support using repetitive reaction steps ensures easy handling and high throughput. Applying this modular approach, peptoids are readily accessible, and their interchangeable side-chains allow for various structures. Thus, peptoids can easily be tuned in their solubility, their spatial structure, and, consequently, their applicability in various fields of research. Since their discovery, peptoids have been applied as antimicrobial agents, artificial membranes, molecular transporters, and much more. Studying their three-dimensional structure, various foldamers with fascinating, unique properties were discovered. This non-comprehensive review will state the most interesting discoveries made over the past years and arouse curiosity about what may come.
\end{abstract}

\section{Introduction}

When it comes to highly specific materials, nature provides a manifold of unique templates for all sorts of demands. By combining a rather low diversity of building blocks, macromolecules with clearly defined tasks and functions are built. Researchers worldwide use this natural modular approach to build up artificial structures with biological and materials science applicability.

One strategy deals with molecules that mimic the polymorphic compound class of peptides - fascinating polymers that interfere with all areas of life.

\section{A versatile platform for bio-instructive materials: peptoids}

Peptoids are peptidomimetic oligomers that are composed of various $N$-substituted glycine monomers. Since their discovery

\footnotetext{
${ }^{a}$ Institute of Biological and Chemical Systems-Functional Molecular Systems (IBCSFMS), Karlsruhe Institute of Technology (KIT), Hermann von Helmholtz Platz 1, 76344 Eggenstein-Leopoldshafen, Germany. E-mail: braese@kit.edu

${ }^{b}$ Institute of Functional Interfaces (IFG), Karlsruhe Institute of Technology (KIT), Hermann von Helmholtz Platz 1, 76344 Eggenstein-Leopoldshafen, Germany ${ }^{c}$ Institute of Organic Chemistry (IOC), Karlsruhe Institute of Technology (KIT), Fritz Haber Weg 6, 76131 Karlsruhe, Germany
}

in 1992, these unique molecules have found application in all fields of research. Due to its fascinating properties, this versatile compound class is comprehensively outlined in several excellent reviews. ${ }^{1-8}$

Peptoids are structurally strongly related to peptides. They can mimic peptides on their specific side chains. However, compared to related peptides, the side chain is moved from the $\alpha$-carbon to the $\alpha$-nitrogen atom. This formal shift is accompanied by the loss of the ability to form backbone hydrogen bonds and increased conformational flexibility. ${ }^{9-11}$ Conformational constraints can be reintroduced by side-chain and sequence design. ${ }^{12-17}$ Thus, peptoids occur in a multifaceted folding landscape exceeding the structural frame of natural peptides. ${ }^{18,19}$ These three-dimensional structures span helices, ${ }^{20-25}$ nanosheets, ${ }^{26-29}$ and macrocycles ${ }^{4,9,30-32}$ with versatile functions.

Sequence-defined peptoids can be built analogous to peptides via solid-phase peptide synthesis (Scheme 1A). ${ }^{33}$ The method requires $N$-protected peptoid monomers that need to be synthesized before their solid-phase assembly. When it comes to large peptoid libraries, a major disadvantage of this approach is that the monomer preparation's synthetic effort limits both the scale and diversity of every library. Zuckermann 
A

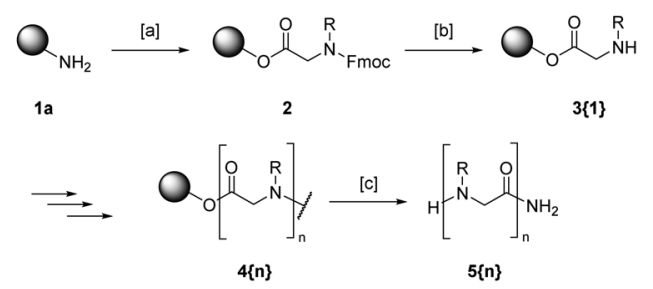

B

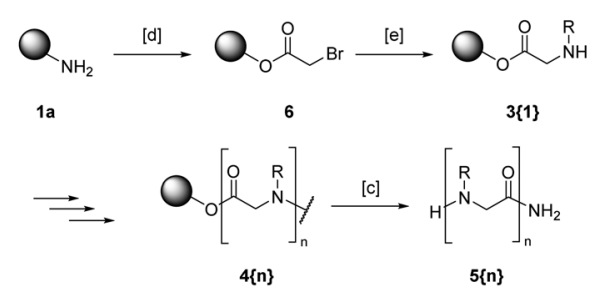

Scheme 1 Solid-phase peptoid synthesis according to Merrifield ${ }^{33}$ (A) or Zuckermann ${ }^{34}$ (B) exemplarily shown for the assembly of peptoid oligomer 5 on a Rink amide resin (1a). [a]: Fmoc-protected peptoid monomer, $N, N^{\prime}$ diisopropylcarbodiimide (DIC), dimethylformamide (DMF); [b] piperidine, DMF; [c]: trifluoracetic acid, methylene chloride; [d]: bromoacetic acid, DIC, DMF; [e]: amine, DMF.

and co-workers overcame this issue when exploring the direct assembly of peptoid monomers on the solid phase. ${ }^{34}$ Nowadays, the so-called submonomer method's approach is the method of choice to synthesize peptoids.

The submonomer approach follows a two-step procedure that includes acetylation with a haloacetic acid, most commonly bromoacetic acid, and a subsequent substitution step with various amine building blocks (Scheme 1B).

For the incorporation of sensitive side-chains, chloroacetic acid has proven to be beneficial. ${ }^{7,35}$ Initially, the haloacetic acid is immobilized on a solid support, mostly a polystyrene resin. Different linker systems that connect the growing peptoid chain to the solid support are applied depending on the desired functionality after cleavage. The linkers are inert towards the reaction steps performed during synthesis and enable both the attachment of the first building block and the cleavage of the entire molecule under mild conditions. ${ }^{36}$

After immobilization of the haloacetic acid, the halide is substituted by an amine with the desired side-chain giving rise to an inconceivably large number of different structural features. The side-chains that have been incorporated into peptoids are as manifold as the resulting peptoids themselves. ${ }^{35,37-42}$

The submonomer method allows for a straightforward and cost-effective assembly of peptoid oligomers. The single coupling steps proceed in less than one hour at ambient conditions. Microwave-assisted techniques can even accelerate the entire process. ${ }^{43-47}$ Moreover, the submonomer method is suitable for automatization. Zuckermann developed the machine synthesis of peptoid oligomers on a common peptide synthesizer. He reported the automated coupling of more than 50 monomeric building blocks in excellent overall yields. ${ }^{7}$

Although the submonomer method is well-established, the stepwise assembly has appeared difficult for longer sequences.

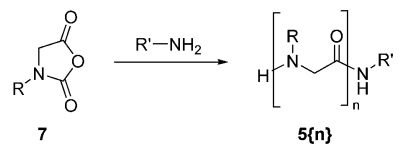

Scheme 2 Ring-opening polymerization of $N$-substituted $N$ carboxyanhydrides $\mathbf{7}$ for the synthesis of polypeptoids $\mathbf{5}$.

Thus, polymerization strategies such as the nucleophilic ringopening polymerization (ROP) of $\mathrm{N}$-substituted $\mathrm{N}$-carboxyanhydrides (NNCAs, 7) have been explored (Scheme 2). ${ }^{48,49}$

Nucleophiles like primary amines initiate the polymerization by a nucleophilic attack on the NNCA, causing ringopening and subsequent release of $\mathrm{CO}_{2}$. The newly formed amine then propagates the polymerization. Linear, brushed, and cyclic polymers with high molecular weight and low polydispersity have been built. ${ }^{50-54}$ However, the method's applicability is limited as bulky $N$-substituents hinder the reaction. In addition, both storage and polymerization of NNCAs require dry and inert conditions what makes the method unhandy. ${ }^{55,56}$

Yet, the high potential of the ROP led to major developments of the synthetic strategy. Less reactive $\mathrm{N}$-substituted $\mathrm{N}$ thiocarboxyanhydrides have been applied to overcome the moisture and water sensitivity of NNCAs. ${ }^{57,58}$ Different initiators such as rare earth metals, ${ }^{58} N$-heterocyclic carbenes ${ }^{59,60}$ or, most recently, LiHMDS, ${ }^{61}$ allowed not only the synthesis of linear peptoid polymers but also of large cyclic structures.

Another approach, the Ugi four-component reaction (Ugi4CR), provides manifold opportunities to introduce a broad structural diversity into peptoid polymers (Scheme 3). ${ }^{62,63}$

The one-pot multicomponent reaction requires an amine (8), a carbonyl (9), an isocyanide (10), and a carboxylate (8) that react under mild conditions either to sequence-defined ${ }^{64,65}$ or, e.g., via step-growth polymerization, to sequence-undefined polypeptoids. ${ }^{66-68}$ Three variable positions and a high tolerance toward various functional moieties make the Ugi method versatile for synthesizing peptoid materials.

\section{Combinatorial libraries as the starting point for the discovery of specific materials}

Combinatorial libraries are collections of multiple combinations of chemically related molecules. The concept was first applied to peptides, ${ }^{48,49}$ and oligonucleotides, ${ }^{50}$ whose modular structure allows synthesizing large libraries using a defined amount of building blocks and identical synthetic steps. Since then, various methods have been applied to diverse substance classes. ${ }^{69-73}$ For some years, combinatorial chemistry is also exploited to synthesize peptoids for various approaches. Herein, we will focus on peptoid libraries that yielded

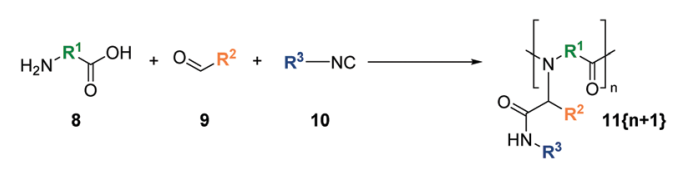

Scheme 3 General scheme of the Ugi reaction to synthesize polypeptoids 11 with diverse side-chains and variable backbone architectures. 
promising compounds with application in both materials science and biomedical research.

\section{One-bead one-compound (OBOC) libraries}

One-bead one-compound (OBOC) libraries were firstly described by Lam. ${ }^{74} \mathrm{He}$ discovered that multiple copies of a distinct peptide are present on one bead after incubation with a certain amino acid. Using a split-and-pool synthetic approach, numerous beads carrying one compound each are synthesized (Fig. 1).

The approach has shown to be suitable for peptoid syntheses up to several million compounds. ${ }^{40,75-77}$

We applied the split-and-pool approach on the IRORI technology to perform a large-scale synthesis of certain peptoids. ${ }^{75,78}$ The reaction cycles were carried out in commercially available nano- up to macro-reactors equipped with glass coated radiofrequency tags allowing for the easy follow up of each building block coupling. Eventually, the synthesis results in higher yields of several milligrams compared to the OBOC strategy.

While the IRORI technology targets the large-scale synthesis of combinatorial libraries, most OBOC libraries contain an infinitesimal amount of a certain compound. Moreover, they span an incredibly high number of different molecules rendering it impossible to monitor every peptoid during the whole synthetic approach. Usually, the assembled oligomers are screened for their specific value while being attached to the resin. ${ }^{79,80}$ The outstanding outcomes of studies, including OBOC libraries, will be outlined throughout this review.

To generate versatile libraries in the positional scanning format, one peptoid monomer of a certain sequence is exchanged simultaneously. An iso-reactive mixture of different amines is added to the growing chain in one position of a defined sequence. Thus, peptoids consisting of equal building blocks riddled with one variable monomer are built. The method allows for the rapid identification of side-chains with decisive effects on the peptoid function (Fig. 2). ${ }^{81,82}$

\section{SPOT arrays}

Besides polystyrene beads, cellulose membranes have been employed for the assembly of peptoid arrays. ${ }^{83}$ These hydrophilic membranes allowed for synthesizing peptoid libraries by pipetting single droplets of non-volatile reagent solutions to defined spots on the solid support. ${ }^{4,83}$ Initially, this so-called SPOT-synthesis was discovered by Ronald Frank. ${ }^{84,85}$ He considered the droplets as micro-reactors that create the



Fig. 1 Generation of an OBOC library via split-and-pool synthesis exemplarily shown for a trimer library consisting of two different building blocks.

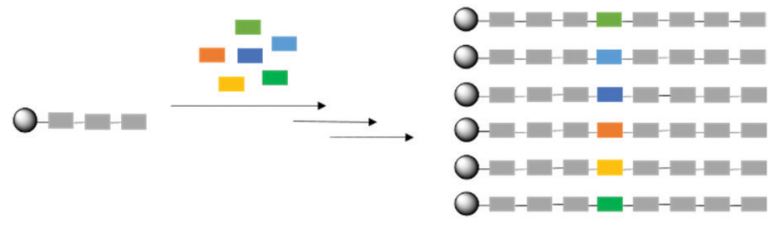

Fig. 2 Design of a library of peptoid octamers in the positional scanning format.

environment for solid-phase synthesis. Thereby, the size of the droplets is determined by the physical properties of both the membrane and the solvent and the dispensed volume.

We applied the SPOT technique for the assembly of a combinatorial peptoid library. ${ }^{44}$ Using microwave irradiation and optimized reaction conditions, 96 dipeptoids were successfully synthesized on a cellulose membrane. Heine et al. even reported the assembly of an array containing 8000 different oligomers. ${ }^{83}$ However, the SPOT synthesis proved not as efficient as the immobilization of peptoids on microarrays.

\section{Peptoid microarrays}

High content combinatorial syntheses generate large compound libraries that need to be screened for their functionality. To single out promising hits, microtiter plates are commonly applied. Eventually, high throughput screenings have been developed by automated read-out methods in microtiter plates and miniaturized microarrays. ${ }^{69,86-88}$ On the latter, compounds libraries are immobilized on a chemically modified glass surface either by post-synthetic attachment or in situ assemblies. ${ }^{89-95}$

The straightforward approach for the synthesis of peptoids renders them ideal candidates for microarray preparations. Li et al. developed a photolithographic procedure that allowed for the targeted incorporation of certain amines. ${ }^{91}$ Thus, they performed the acetylation step with a light-sensitive glycolic acid which released a hydroxyl moiety after UV irradiation. Activated with tosyl chloride, the hydroxyl group was substituted by the desired amine (Scheme 4).

We employed a laser-assisted process to produce highdensity peptoid microarrays using laser-induced forward transfer technology (LIFT). ${ }^{96}$ Applying this technology, donor slides were coated with nanometer-thin layers of either diisopropylcarbodiimide (DIC) as a coupling reagent, bromoacetic acid, or the corresponding amine. The alternate stacking of the donor slide on top of an acceptor slide enabled the spots transfer of the reagents by short laser pulses. Peptoid assembly occurred after heating the educts to $90{ }^{\circ} \mathrm{C}$ (Scheme 5). An additional

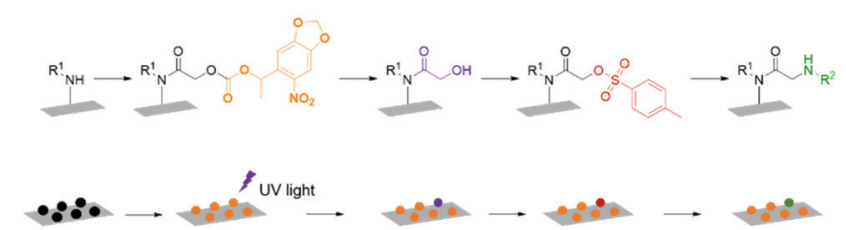

Scheme 4 Photolithographic approach for the assembly of peptoid microarrays. 


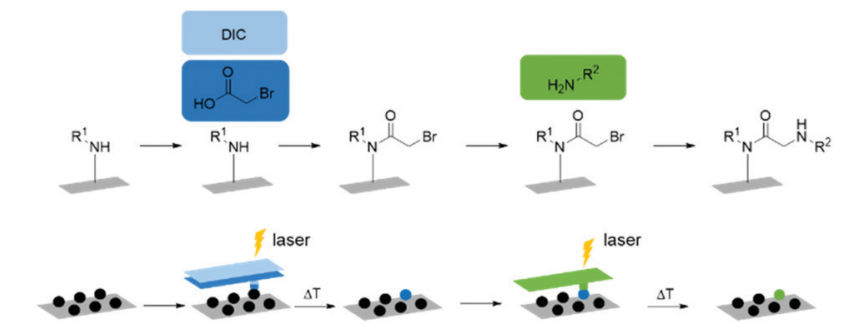

Scheme 5 Laser-assisted stacking of nanolayers to assemble peptoid microarrays.

spotting of a matrix-assisted laser desorption ionization (MALDI) matrix using the same method allowed for the rapid identification of the synthesized peptoids.

\section{Identification of hit compounds}

Many combinatorial approaches for peptoid synthesis, such as the OBOC strategy, need elaborate analytical technologies to identify single hit compound sequences. ${ }^{97-99}$ Edman degradation has been employed for this purpose. ${ }^{74,80,100}$ However, the duration and costs of this method afforded the development of different sequencing techniques.

Thakkar et al. outlined that a partial Edman degradation followed by MALDI mass spectrometry of the resulting fragments instead of single building blocks allowed for a quick and inexpensive alternative to this method. ${ }^{101}$ Other approaches used tandem mass spectrometry (MS) to determine the sequence of hit compounds. ${ }^{102,103}$ The incorporation of different scaffolds enabling a ring-opening after screening even allowed for the sequencing of cyclic peptoids using tandem MS. ${ }^{104-106}$

Besides these direct techniques to identify single peptoids, tags have been employed to circumvent difficult sequencing methods. Pirrung et al. developed an aryl fluoride tag that supported identifying distinct peptoids via ${ }^{19} \mathrm{~F}$ NMR spectroscopy. As the chemical shift of aryl fluorides is highly dependent on the substitution pattern of the aromatic system, the tags could be easily detected. ${ }^{107}$ Shin et al. reported synthesizing a DNA-encoded OBOC-library composed of more than 11 million cyclic peptoids whose hit compounds were identified via polymerase chain reaction (PCR) amplification of the assigned nucleic acids. ${ }^{108}$ Kang et al. published an encoding method based on dual-modal identifiers with a graphical pattern and a Raman signal. ${ }^{109}$

\section{Combinatorial libraries for the discovery of peptoid foldamers}

Peptoids are characterized by a rapid amide bond cis-trans isomerization and high conformational flexibility. ${ }^{9-11,18,19}$ Thus, versatile foldamers such as helices, ${ }^{20-25,110}$ loops, ${ }^{111}$ nanosheets, ${ }^{26-29}$ ribbon-like structures, ${ }^{112} \omega$-strands ${ }^{113}$ or nanotubes ${ }^{32,114}$ have been discovered. Foldamers are oligomers that strongly tend to self-assemble into defined secondary structures. ${ }^{115}$ Combinatorial libraries have emerged as powerful tools that helped understand the influence of certain structural features on this self-assembly.

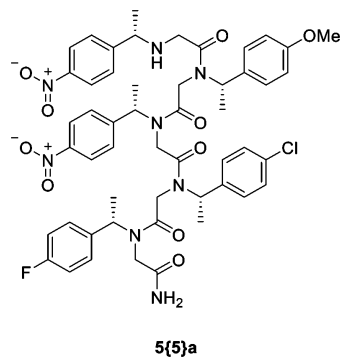

Fig. 3 Pentamer $\mathbf{5}\{\mathbf{5}\}$ a that showed to self-assemble in a right-handed helix. ${ }^{116}$

For example, Armand et al. compared the circular dichroism (CD) and nuclear magnetic resonance (NMR) spectra of a peptoid library partially consisting of chiral building blocks. They picked one particular pentamer for a comprehensive structure determination (Fig. 3).

Peptoid 5\{5\}a formed stable cis-amide bonds and selfassembled them in a right-handed helix with a periodicity of three residues per turn. As the structural data were consistent with other library members, Armand et al. assumed that oligopeptoids with $\alpha$-chiral side-chains might adopt identical spatial structures. ${ }^{116}$ Based on this initial study, the influence of the amount, type, and the position of $\alpha$-chiral side-chains on the helicity of the entire molecule was examined using various peptoid libraries. ${ }^{25,117-121}$ Later studies carried out by different working groups added further side-chains to the growing list of cis-bond inducers (Table 1). ${ }^{14-16,19,23,42,122,123}$

Burkoth et al. applied this knowledge to a combinatorial split-and-pool peptoid library of 3456 amphiphilic 15-mers that consisted of 15 different building blocks. Each sequence variant was placed in a microtiter plate where aqueous conditions allowed for the assembly of the peptoid strands. 1Anilinonaphthalene-8-sulfonate, a dye that exhibits a weak fluorescence in an aqueous solution but strong fluorescence when bound to a hydrophobic entity, allows monitoring helical bundles. Tandem MS sequencing, resynthesis of promising hits, and subsequent analyses revealed peptoid sequences capable of forming stable helical bundles (Fig. 4). ${ }^{21}$

Solid and solution phase studies of a peptoid library containing aniline derivatives as side-chains showed a strong trans-amide preference for these building blocks. ${ }^{13}$ Later on, stabilized trans-amide bonds were found in $\mathrm{N}$-alkoxy and $N$-hydroxy peptoids as well. ${ }^{125,126}$

The manifold spatial structures adopted by peptoid oligomers are comprehensively outlined in several excellent reviews. ${ }^{3,4,6,9,56}$ Based on various sequence-structure analyses, nowadays, both the rational design and the computer-aided structure prediction of peptoid foldamers is possible. .,5,113,127-131 $^{-13}$

\section{Combinatorial peptoid libraries in materials science}

Peptoids show a broad range of tunable physicochemical properties. Due to their modular assembly and sequence specificity, they find application in new materials design and materials science..$^{1,3,132,133}$ The class of peptoid materials 
Table 1 Examples of cis-bond inducing side-chains

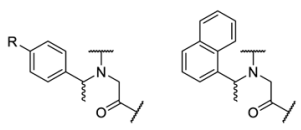

$25,116,123,124$

$\alpha$-Chiral aromatic residues<smiles>CCC(C)N(CC(=O)C(C)C)CC(C)C</smiles>

$\alpha$-Chiral aliphatic residues

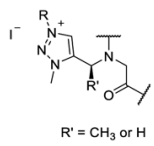

Cationic triazolium-type residues<smiles>CC(C)CN(C(=O)CC(C)(C)C)C(C)(C)C</smiles>

Tert-butyl residues<smiles>CCN(CC(=O)CC(C)C)CC(F)(F)F</smiles>

Trifluoroethyl residues<smiles></smiles>

Tetrafluoroethyl residues

$$
\text { 赵 }
$$

Cationic alkyl ammonium ethyl residues

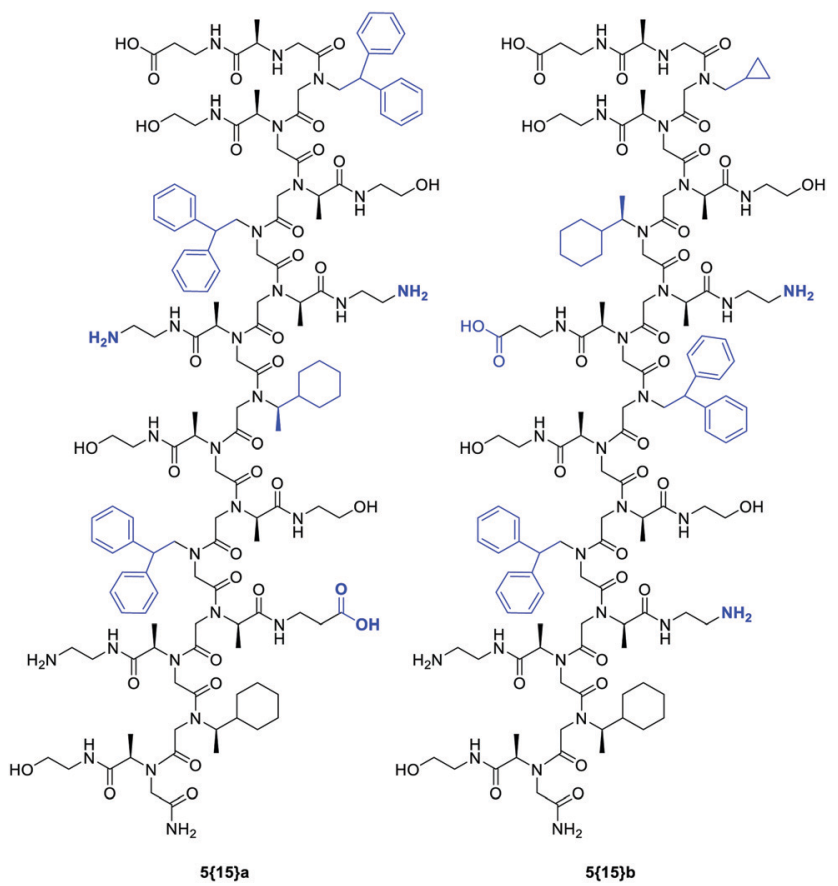

Fig. 4 Two examples of peptoid 15 -mers $\mathbf{5}\{\mathbf{1 5}\}$ that assembled in helical bundles. Variable positions are marked in blue. ${ }^{21}$

comprises, i.e., bioinspired materials, metal chelators, and catalysts.

\section{Peptoids as a scaffold for potent catalysts}

Since peptides often mimic the partial function of proteins or receptor ligands, they have been of interest for pharmacological applications for decades. In addition, many proteins are enzymes that display a variety of catalytic functions. As enzymes have chemo- and stereoselective catalytic activity, they are highly attractive entities for many types of materials. Because peptides themselves are rather unstable in common and biological environments, researchers focus on synthesizing peptidomimetics with better pharmacological and biophysical properties due to proteolytical digestions. Common peptidomimetics are classified into different classes such as molecules with peptide characters like modified peptides, D- and betapeptides, peptoids, foldamers, and small molecule mimetics like structural and mechanistic mimetics. ${ }^{134}$

As peptoids belong to the class of peptidomimetics, they can mimic biological entities' catalytic properties. Therefore, bioinspired peptoid materials can function as organo-catalysts or artificial enzymes with designed artificial properties. Due to their side-chain variety, peptoids can be constructed to represent a defined spatial structure around the catalytic center. In addition, their chemical inertness towards a high number of catalytic reactions makes them a potent scaffold for efficient catalysts. The Maayan working group took advantage of the modular structure of peptoids to synthesize versatile organocatalysts on the solid phase. The combination of in silico and in vitro methods led to the discovery of efficient electrocatalysts for homogeneous water oxidation, ${ }^{135,136}$ highly enantioselective catalysts, ${ }^{137,138}$ and even resin-bound, recyclable peptoid catalysts for oxidation reactions of benzyl alcohol. ${ }^{139}$ Izzo et al. synthesized small libraries of peptoid macrocycles via solidphase submonomer synthesis and subsequent head-to-tail cyclization. Investigation of the catalytic properties of these macrocycles revealed enantioselective phase-transfer catalysts for the synthesis of $\alpha$-amino acids. ${ }^{140,141}$

De la Torre et al. used the Ugi-4CR to build up prolyl peptide-peptoid hybrid catalysts 12 (Scheme 6). ${ }^{142}$

A combinatorial library of 13 different peptoids was then tested about their catalytic activity in an asymmetric Michael addition of aldehydes to nitroolefins. The combinatorial approach allowed for the identification of structural features crucial for both excellent stereocontrol and catalytic efficiency (Scheme 7). ${ }^{142}$

The Wessjohann working group applied the Ugi-4CR to synthesize various peptoid-based dimers, which had an alkyne moiety introduced by the amine component in common. In a

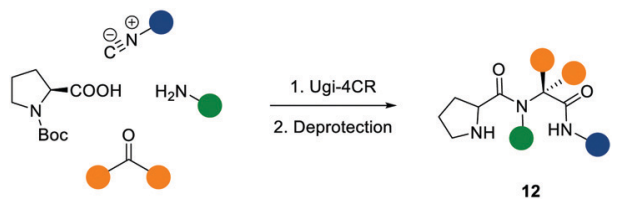

Scheme 6 Ugi four-component reaction (Ugi-4CR) for the combinatorial synthesis of prolyl peptide-peptoid hybrid catalysts of general structure $12 .{ }^{142}$ 


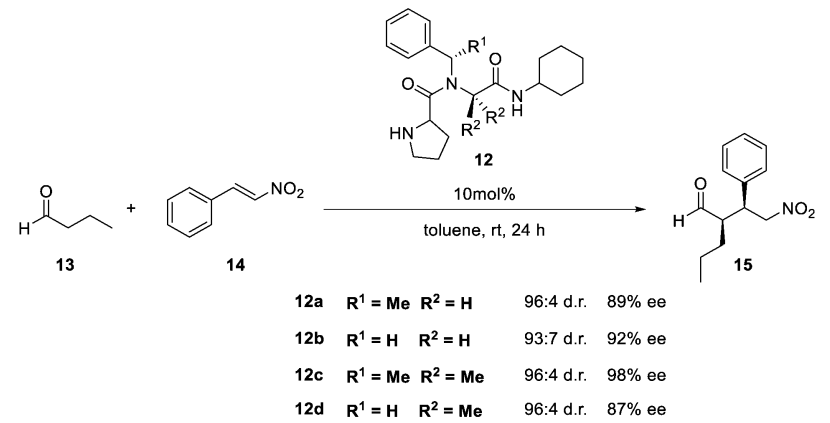

Scheme 7 Examples of structurally similar peptide-peptoid hybrids with different enantioselectivities in asymmetric Michael additions. ${ }^{142}$

combinatorial approach, they put three alkyne peptoids in the same reaction vessel to simultaneously perform a coppercatalyzed homocoupling (Glaser reaction). By doing so, a small library of 1,3-diyne-linked peptoids $\mathbf{1 6}$ was formed (Scheme 8A). ${ }^{143}$ Besides this proof of principle, they applied combinatorial Ugi-4CRs to build selenocysteine containing peptoids $17^{144}$ as well as cryptands, cages, and cryptophanes with potential applicability in catalysis (Scheme $8 \mathrm{~B}$ and C).${ }^{145}$

\section{Peptoids as selective metal chelators}

Peptoid-mediated metal chelation can enable catalytic transformations, enhance metal-based luminescence, or isolate certain metal ions from heterogeneous mixtures. The Francis group used combinatorial chemistry to identify selective metal chelators that extract certain metal species like chromium(vI), uranyl-ions, or mercury(II) from water. ${ }^{146-148}$ A combinatorial split-and-pool synthesis using five amines capable for $\mathrm{Cr}^{4+}$ coordination and two amines adding nonbonding interactions

A

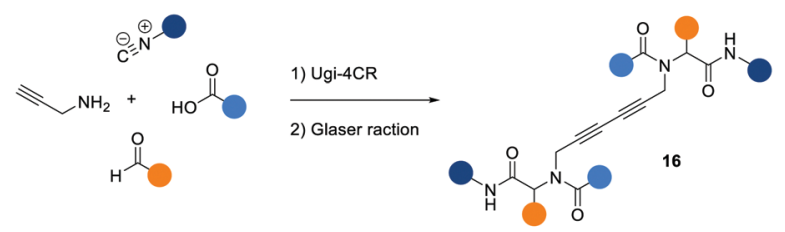

B

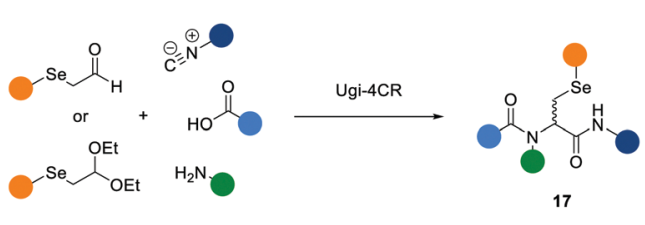

C
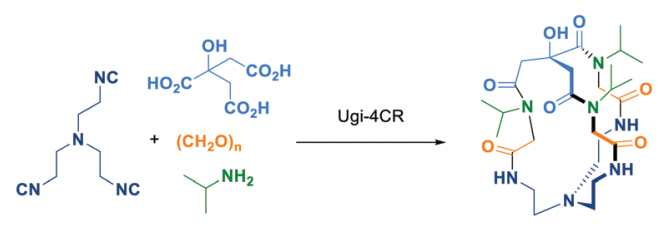

18

Scheme 8 Examples of combinatorial peptoid libraries synthesized via Ugi-4CRs to build 1,3-diyne-linked peptoids $16(\mathrm{~A}),{ }^{143}$ selenocysteine containing peptoids 17 (B), ${ }^{144}$ and cryptands such as structure 18 (C). ${ }^{145}$ was performed on polyethylene glycol (PEG)-grafted polystyrene beads (Fig. 5).

Thus, 2401 different peptoid tetramers were built on a solid support and incubated with a solution containing $\mathrm{CrO}_{3}$. After filtration and washing, diphenylcarbazide was added to monitor $\mathrm{Cr}^{4+}$ binding sequences. Thereby, the imaging of the beads carrying chelating peptoids was based on the oxidation of the carbazide by $\mathrm{Cr}^{4+}$, causing an unambiguously detectable color change. Colored beads were separated, the tetramers were released from the resin and sequenced using MALDI-TOF MS/MS spectrometry (Scheme 9).

Subsequent assays to verify the hit sequences revealed $\mathrm{Cr}^{4+}$ ligands with strong structural similarities: the tetramers with the highest affinity consisted of a nonchelating residue at the N-terminus followed by a cysteamine side-chain (Table 2). Interestingly, no peptoid with the thiol moiety at one of the two termini was identified as a hit sequence. ${ }^{146}$

The same combinatorial peptoid library was evaluated for its binding affinity towards uranyl species. With the help of an arsenazo III dye, three structurally related peptoid ligands that significantly differed from the $\mathrm{Cr}^{4+}$ chelating tetramers were identified (Table 2). However, the binding affinity was rather low, implying further research using alternative side-chains. ${ }^{147}$

A selective binder for mercury(II) was identified with the help of a 7203-membered OBOC library consisting of the four peptoid monomers shown in Fig. 5, a small spacer, and the amino acid proline as a turn-inducing unit (Table 2). The beads were exposed to $\mathrm{Cr}^{4+}, \mathrm{Pb}^{2+}, \mathrm{Cd}^{2+}$, and $\mathrm{Hg}^{2+}$ to determine particular hit sequences. The most promising peptoid was attached to pyrene as a fluorophore with a substantial decrease in fluorescence upon mercury binding. Thus, a potent peptoidbased mercury sensor was developed. ${ }^{148}$

The Francis group applied their method to human blood as well. To find selective cadmium chelators, the 7203-membered peptoid library mentioned above was incubated with a cell culture medium containing $\mathrm{Cd}^{2+}, \mathrm{Fe}^{2+}, \mathrm{Mn}^{2+}$, and $\mathrm{Zn}^{2+}$ ions, presenting the typical ingredients of human serum. Cadmium chelating peptoids were identified with the help of cadion, a

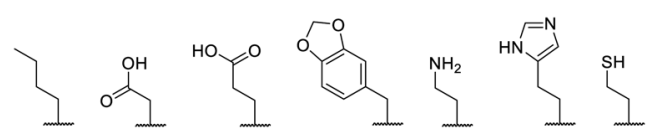

Fig. 5 Side-chains of peptoid monomers used by the Francis working group to find selective metal chelators. ${ }^{146-148}$

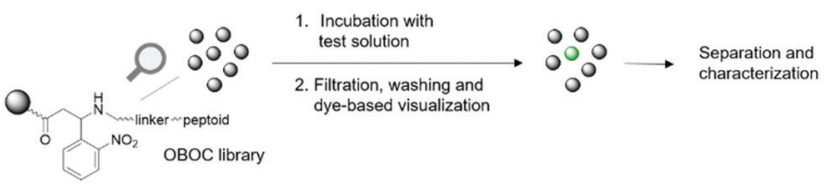

Scheme 9 General approach of the Francis working group to identify efficient metal chelators via combinatorial split-and-pool OBOC peptoid synthesis. ${ }^{146-149}$ 
Table 2 Examples of metal chelating peptoids identified with the help of combinatorial libraries

Metal Peptoid ligands

Table 2 (continued)

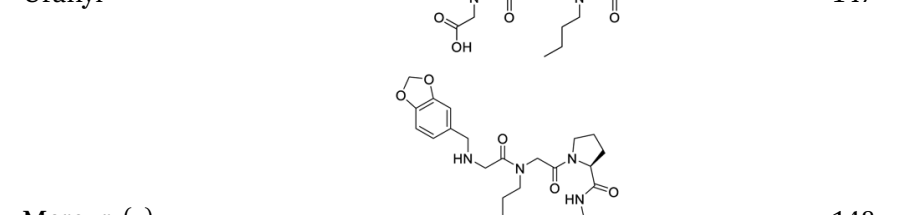

Mercury(II)

Cadmium(II)

Copper(II)

Ruthenium(II)

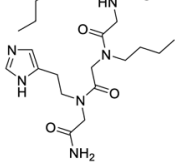

Zinc(II)

Nickel(II)

Metal Peptoid ligands

dye that turns pink upon cadmium complexation. The most efficient binders were thoroughly characterized and examined in the presence of human serum. Thus, the working group pointed out selective cadmium(II) chelators with unprecedented performance even in a highly complex environment (Table 2). ${ }^{149}$

A set of peptoid trimers with two copper(II) chelating units, as well as non-coordinating peptoid monomer, was designed by Mayaan et al. By varying the nature and position of the noncoordinating unit, they found selective binders for $\mathrm{Cu}^{2+}$ that were even able to remove the ions from the natural copperbinding protein metallothionein. ${ }^{150}$ The working group also applied their peptoid design to build potent ruthenium(II), ${ }^{151}$ cobalt(II), ${ }^{152}$ and zinc(II) ${ }^{153}$ chelators (Table 2).

The Kirshenbaum working group identified peptoid-based nickel(II) chelators with the help of bench-top X-ray fluorescence (XRF, Table 2). For XRF, highly energetic X-rays eject an electron from a $1 \mathrm{~s}$ or $2 \mathrm{~s}$ orbital. The resulting vacancy is filled by electron transitions that emit photons with characteristic emission lines. The method quantifies the elemental composition of a certain sample and thus the complexation behavior of potent ligands. The working group established the methodology as a fast screening method for combinatorial resin-bound peptoid libraries. ${ }^{154}$

Ricano et al. analyzed a split-and-pool library of peptoid tetramers regarding their ability to bind lanthanide ions. They found the peptoid scaffold to be a readily accessible, versatile platform for the future development of efficient lanthanide ligands. ${ }^{155}$

Besides chelation of single metals, OBOC libraries were employed to identify peptoid ligands of multimetallic clusters such as the $\left[\mathrm{Co}_{4} \mathrm{O}_{4}\right]$ cubane cluster. Inspired by the crystal structure of photosystem II, Nguyen et al. synthesized a splitand-pool library out of five different building blocks creating 125 resin-bound peptoid heptamers. The $\left[\mathrm{Co}_{4} \mathrm{O}_{4}\right]$ clusters were added to the beads and hit sequences were directly recognized by the dark green color of the bound $\left[\mathrm{Co}_{4} \mathrm{O}_{4}\right]$. High-affinity sequences were identified after exposure to increasing concentrations of acetic acid. Sequencing with tandem MS techniques revealed heptapeptoid 19, resynthesized and analyzed via NMR spectroscopy (Fig. 6). Thus, the study substantially contributed to the understanding of metallopeptoid dynamics. ${ }^{156}$

Sing et al. attempted to bridge metal chelation and biological activity with the help of OBOC libraries. As a proof of principle, they designed a large library consisting of the potent metal chelator 1,4,7,10-tetraazacyclododecan-1,4,7,10-tetraacetic 


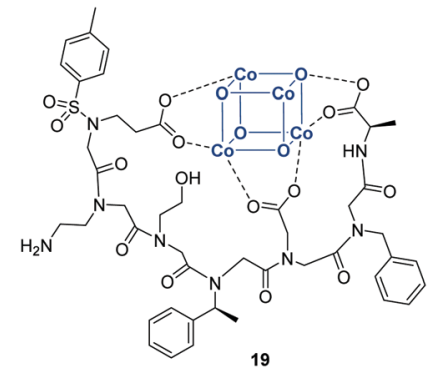

Fig. 6 Hexapeptoid 19 capable to bind the $\left[\mathrm{CO}_{4} \mathrm{O}_{4}\right]$ cubane cluster (blue). ${ }^{156}$

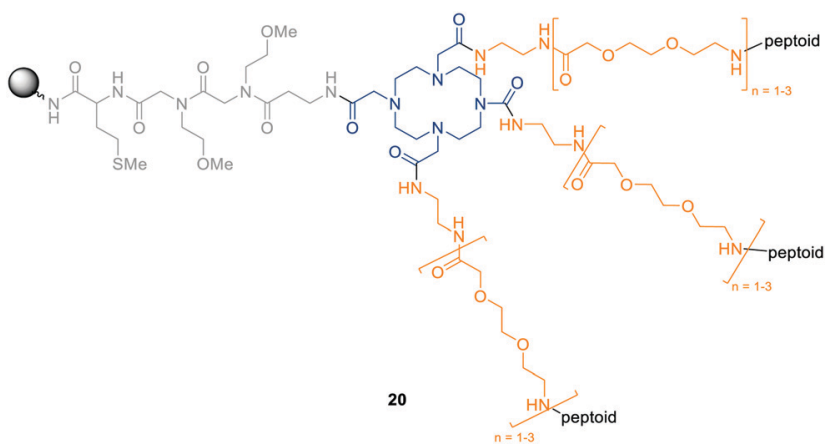

Fig. 7 General structure of the OBOC library designed by Sing et al. ${ }^{76}$ DOTA (blue) is immobilized on the resin and attached to three copies of the same peptoid separated by a variable amino-ethyloxy-acetyl spacer (orange).

acid (DOTA) and three corresponding peptoid oligomers (Fig. 7). ${ }^{76}$ Using the split-and-pool technique, they were able to perform the submonomer method directly on the modified DOTA scaffold. With the assembly of peptoid hexamers using eleven different building blocks, a theoretical diversity of 153600 compounds was achieved. Their design will allow for a multivalent target binding together with the possibility to monitor each molecule via versatile imaging techniques such as magnetic resonance imaging (MRI) or positron emission tomography (PET). ${ }^{76}$

In an interplay with DOTA, peptoids can function as targeting and imaging unit at the same time. As reported by Udugamasooriya and colleagues, other approaches used combinatorial synthesis to generate sensitive chemical exchange saturation transfer (CEST) agents. Thus, DOTA was immobilized on a TentaGel resin. The three remaining appendages were used for dipeptoid synthesis with eight chemically diverse amines resulting in an 80-membered library. After europium(III) complexation and transfer of the beads into a microtiter plate, CEST imaging was performed to identify novel structural features to increase CEST contrast. As a result, they found non-bulky negatively charged side-chains such as carboxyethyl or carboxybutyl close to the europium(III) metal center to enhance the CEST signal strongly. ${ }^{157,158}$

\section{Peptoid-derived bioinspired materials}

Peptoids and their foldamers serve as a scaffold for diverse bioinspired materials. ${ }^{1,3,132,133}$ The applications of these peptoid-based materials span molecular recognition and sensing, ${ }^{132,159-162}$ membranes, ${ }^{29,163,164}$ antifouling coatings, ${ }^{165-169}$ the assembly and arrangement of nanoparticles ${ }^{170-175}$ and chromatography. ${ }^{176-179}$ Some of these unique materials emerged with the help of combinatorial approaches.

In a combinatorial Ugi-4CR step-growth polymerization, Stiernet et al. assembled peptoid-based polymers. They introduced diversity with the help of various amino acid derivatives, isocyanides, and aldehydes to influence the thermal properties and the $\mathrm{pH}$ responsiveness of the respective polymers. The systematic permutation of one building block allowed for investigating a structure-to-function relationship from the peptoid backbone or the respective side-chains. As a result, they found different glass transition and degradation temperatures of polymers in the same mass range (Table 3 ). ${ }^{68}$

Thermoresponsive materials have gained attention in biomedical research, e.g., for drug delivery applications. ${ }^{180,181}$ Many research groups use the highly tunable peptoid scaffold to adjust the phase transition behavior of polymers and to add further stimuli-responsive properties to design smart materials. $^{182,183}$

The broad structural diversity of peptoids does not restrict their polymers to one type of application but allows for their use as versatile, sophisticated material. As an example, Statz et al. were the first to report the antifouling properties of polypeptoid 21 (Fig. 8). ${ }^{165}$

The group mimicked the known antifouling polymer poly(ethylene glycol) with the methoxyethyl side-chains. Since this initial study, many peptoid coatings that resist protein or cell attachment have been designed. ${ }^{166,169,184-189}$ A critical grafting density, conformational flexibility, and high hydration have been considered crucial for antifouling polypeptoids.

Besides functioning as diverse materials, peptoid oligomers have proved capable of modifying the crystal growth of various molecules. ${ }^{190,191}$ Controlling crystallization is especially

Table 3 Thermal properties of a combinatorial Ugi-4CR step-growth polymerization peptoid library. ${ }^{68} T_{\mathrm{g}}=$ glass transition temperature; $T_{\mathrm{d}}=$ degradation temperature

\begin{tabular}{|c|c|c|}
\hline \multirow[t]{5}{*}{ Structure } & $T_{\mathrm{g}}\left[{ }^{\circ} \mathrm{C}\right]$ & $T_{\mathrm{d}}\left[{ }^{\circ} \mathrm{C}\right]$ \\
\hline & 169 & 259 \\
\hline & 162 & 262 \\
\hline & 98 & 251 \\
\hline & 99 & 344 \\
\hline
\end{tabular}




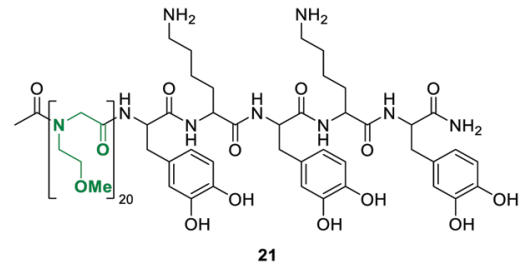

Fig. 8 Polypeptoid $\mathbf{2 1}$ with methoxyethyl side-chains (green) mimics the antifouling polymer poly(ethylene glycol). ${ }^{165}$

essential for the design of inorganic materials. Peptoids' good thermal and chemical stability was exploited to create welldefined inorganic crystals.

As an example, Li et al. investigated the influence of chemically diverse peptoids on zeolite L crystallization. Zeolites are microporous aluminosilicates that are commonly used as adsorbents or catalysts. Surprisingly low concentrations of peptoids $(<1 \mathrm{wt} \%)$ enabled the crystal growth. However, chain length and the type of the N-terminal hydrophilic residue affected the morphology of zeolite L: while a peptoid composed of six methoxyethyl and an N-terminal hydroxyethyl side-chain initiated the growth of purely crystalline zeolite $\mathrm{L}$, the exchange of the hydroxyethyl by an aminoethyl residue or the reduction of the six methoxyethyl side-chains to only one led to more amorphous products. Moreover, distinct side-chain functionalities selectively altered the length-to-wide aspect ratio of cylindrical zeolite L crystals: an incorporation of several hydrophobic benzyl side-chains led to shorter zeolite L cylinders while an increase of methoxyethyl residues extended their lengths (Fig. 9). ${ }^{192}$

Chen et al. comprehensively studied peptoids' structural motifs crucial to promoting calcite growth and thus $\mathrm{CO}_{2}$ fixation. After they fed a solution of aqueous $\mathrm{CaCl}_{2}$ and the peptoid of interest with $\mathrm{CO}_{2}$ and $\mathrm{NH}_{4}$ vapor, the working group found compounds consisting of aminobutyl, carboxyethyl, and substituted phenylethyl side-chains that modified both the morphology and the growth rate of calcite. ${ }^{193,194}$

Besides metal complexes, peptoids can modify the growth of ice crystals. With the help of a peptoid oligomer library containing a different amount of methyl and hydroxyethyl side-chains, Huang et al. investigated structural features responsible for antifreeze activity. The monodispersity of the OBOC library allowed them to identify the dual-action peptoid $5\{3\} a$ that did inhibit not only ice growth but also reduced the melting temperature (Fig. 10). ${ }^{195}$ Recently, Huang et al. confirmed the

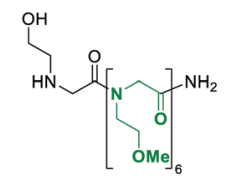

$5\{7\} \mathbf{a}$

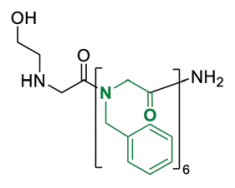

$5\{7\} \mathbf{b}$
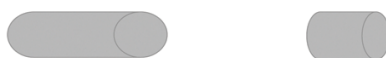

Fig. 9 Influence of peptoid side-chains on cylindrical zeolite L crystals (gray). ${ }^{192}$

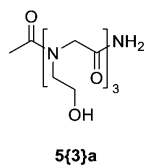

Fig. 10 Peptoid 5\{3\}a reduces the melting temperature and inhibits the growth of ice. ${ }^{195}$

antifreeze properties of certain peptoid oligomers with methyl, ethyl, hydroxyethyl, and aminoethyl side-chains. They found a peptoid similar to peptoid $5\{3\} a$, but equipped with six instead of three hydroxyethyl residues, the most potent antifreeze agent. $^{196}$

Zuckermann et al. built selective antibody mimetics based on functionalized peptoid nanosheets. ${ }^{28,197}$ Several recognition domains were incorporated into these stable foldamers using combinatorial chemistry. The domains, more precisely conformationally constrained loop regions, were designed to exhibit certain sequences of hydrophilic and hydrophobic building blocks. Seven diverse hydrophilic and 13 hydrophobic amines were varied in these sequences, resulting in a combinatorial library of 254 hexameric patterns. The hexamers were extended on both sides with nine alternating aminoethyl and phenylethyl side-chains at the $\mathrm{N}$-terminus and nine alternating carboxyethyl and phenylethyl side-chains at the C-terminus. The balanced mix of hydrophobic and hydrophilic monomers allowed for the formation of peptoid nanosheets that displayed chemically diverse loop regions on the polar surface (Fig. 11). Using the Foerster resonance energy transfer (FRET) technique, sequences binding the anthrax protective antigen, a heptameric protein subunit of anthrax toxin were identified. Thus, the Zuckermann group developed a robust, bioinspired antibody mimetic with a huge binding surface that enables tunable, multivalent interactions. $^{28}$

However, the power of nanosheets is not limited to antibodies. Hu et al. verified the remarkable sensing properties of peptoid nanosheets. Displaying peptoid loops capable of binding amyloid $\beta$ on the surface, the nanosheet helped identify sera derived from patients with Alzheimer's disease. The dense distribution of the highly affine peptoid loops allowed for the specific binding of amyloid $\beta$ despite the multicomponent character of human sera. As the current diagnosis of Alzheimer's disease is based on symptoms that are usually evident years after the pathological process, the peptoid nanosheet holds great promise toward an early-stage diagnosis. ${ }^{198,199}$

In addition to peptoid nanosheets, single-walled carbon nanotubes (SWNTs) have been shown to scaffold protein recognition. SWNTs fluoresce in the near-infrared region through exciton recombination. They serve as sensitive optical

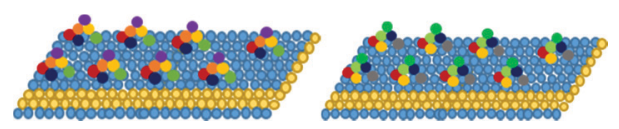

Fig. 11 Nanosheets presenting different combinatorial loop structures on their polar surfaces. ${ }^{28}$ 


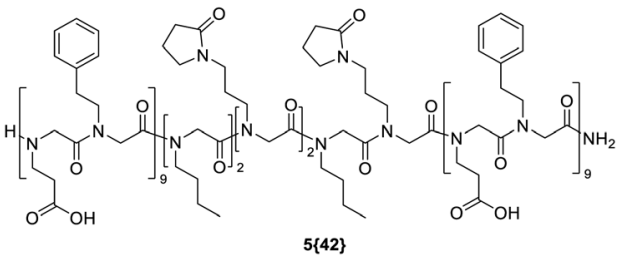

Fig. 12 Peptoid polymer $\mathbf{5}\{\mathbf{4 2}\}$ is one exemplary structure that adsorbs to SWNTs. ${ }^{200}$

nanosensors with polymers immobilized on their surface as binding processes modulate the exciton recombination rate or bandgap. Chio et al. screened a peptoid library for its ability to adsorb to SWNTs and to stabilize the overall structure. Interestingly, polymers consisting of 14 or 18 dipeptoids with carboxypropyl and phenyl ethyl side-chains adsorbed to SWNTs while a derivative consisting of only nine carboxyethylphenylethyl repeats did not.

Moreover, a positive charge introduced by an aminoethyl residue hindered adsorption, whereas a negatively charged carboxyethyl side-chain seemed crucial. With the most potent polymer $\mathbf{5}\{\mathbf{4 2}\} \mathbf{b}$ in its hands, the group was able to selectively detect a lectin that remained active towards its target sugars even when bound to the peptoid-SWNT nanosensor (Fig. 12). ${ }^{200}$

Besides artificial antibodies, the capability of peptoids to function as transfection reagents was studied. For the sake of understanding the structure-to-function relationship of gene delivery properties, a library of peptoid oligomers varying in their length, overall shape, hydrophobicity, and periodicity was synthesized. As the automated synthesis of the single peptoids allowed for high purities, their capability to form peptoid-DNA complexes, withstand proteolytic degradation, and transfect different cell lines in vitro was examined without further time-consuming purification. The investigation of the structure-function relationship revealed that the motif cationicaromatic-aromatic promotes efficient gene delivery (Fig. 13). However, while the 36 -mer $\mathbf{5}\{\mathbf{3 6}\}$ consisting of a repeating motif of an aminoethyl side-chain followed by two phenylethyl residues showed optimal activity, derivatives in which the phenylethyl side-chains were replaced indolylethyl or 4hydroxyphenylethyl failed in the transfection assay. Interestingly, even the shortening of phenylethyl to benzyl side-chains resulted in a lower transfection activity. ${ }^{201}$

\section{The achievements of combinatorial peptoid libraries in biology and medicine}

Although peptoids are an emerging class of oligomers for diverse applications in materials science, most research in peptoid chemistry focuses on biological questions. Especially in pharmaceutical applications, peptoids serve as a versatile compound class for designing new therapeutics and diagnosis tools. Nowadays, potent derivatives for cellular transport, protein binding, and therapeutics with anti-cancer and antimicrobial activity and even activity against multi-drug resistant bacteria are discovered. . $^{8,129,202,203}$
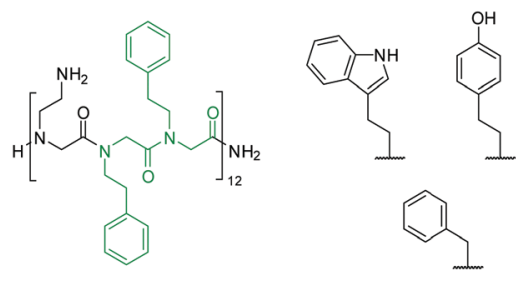

$5\{36\}$

Fig. 13 A polypeptoid capable of serving as transfection reagent. Substitution of the phenylethyl side-chains (green) by indolylethyl, 4-hydroxyphenylethyl or benzyl residues led to a loss of function. ${ }^{201}$

Many hit compounds were found from screenings of large combinatorial libraries. Libraries made by diversity-oriented synthesis (DOS) and biology-oriented synthesis (BIOS) provided structures that would have never been examined by only rational design of single compounds. DOS differs considerably from that used in traditional combinatorial syntheses. To get high synthetic efficiency of structurally diverse molecules, the DOS approach starts with simple materials with a greater variety of core scaffolds, converted into a collection of structurally diverse small molecules in no more than five steps. ${ }^{204-206}$ Therefore, DOS libraries reflect a greater chemical space coverage as they are usually smaller in size and structurally more complex due to their richer stereochemical variation. ${ }^{206}$ BIOSderived libraries in peptoid research usually reflect the variation of well-defined peptide structures, well known for activity in biological systems to enhance, i.e., binding efficiency or pharmacological ADMET (absorption, distribution, metabolism, excretion, and toxicity) parameters.

The studies are so numerous that the subsequent section will only provide an overview of the possible application fields of combinatorial peptoid chemistry in biological research.

\section{Peptoid libraries for the reliable detection of human diseases}

With the help of combinatorial peptoid libraries, diagnostic tools have been developed that allow for the reliable detection of rare or hardly diagnosed pathologies. Previously, Kodadek and colleagues developed peptoids to detect unknown biomarkers that are characteristic of certain diseases. ${ }^{207-209}$ They hypothesized that serum-derived immunoglobulin G (IgG) antibodies from patients would bind to at least one synthetic molecule when exposed to a very large combinatorial library of peptidomimetics. As certain antibodies are more abundant in patients than in the healthy population, the binding should be detectable due to increased signal strengths. They synthesized a split-and-pool 8-mer peptoid library containing seven different side-chains immobilized on microarrays to prove their idea. They exposed their library to sera of mice that developed a syndrome resembling multiple sclerosis. Bound IgG antibodies were visualized with fluorescent secondary antibodies (Fig. 14A), and hit sequences were analyzed using tandem mass spectrometry. In a subsequent blinded study, all identified hit sequences distinguished between sera of pathological and wildtype mice. ${ }^{207}$ 


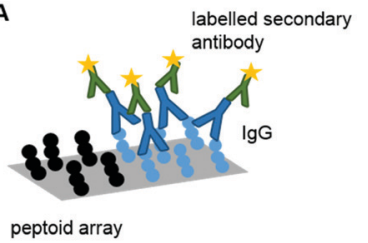

B

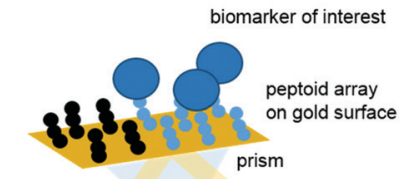

light source

detector

Fig. 14 A: Identification of immunoglobulin G (IgG) binding peptoids with the help of labeled antibodies. B: Surface plasmon resonance imaging for the detection of biomarkers.

Eventually, these microarrays were used with sera of human patients with Alzheimer's disease (AD). Two peptoids were discovered that could distinguish between sera from $\mathrm{AD}$ patients and healthy individuals as well as sera from lupus patients (Table 4$).^{207}$

Furthermore, OBOC libraries containing 100000 compounds (8-mer peptoids, ten different side-chains in five variable positions) were synthesized on TentaGel beads to be used

directly in the following screening step and thus increasing the total amount of peptoids tested in one screen. The immobilized peptoids were screened to bind IgG antibodies against the water channel protein aquaporin 4, known biomarkers for neuromyelitis optica (NMO), a rare autoimmune disease. A secondary screen of promising hit compounds allowed for the exclusion of false-positive hits derived from non-specific resin interactions and, thus, the identification of peptoids that could distinguish between NMO, controls, and other diseases (Table 4). ${ }^{208}$

The extraordinary potential of combinatorial peptoid libraries to serve as diagnostic tools was underlined with the identification of sequences that could selectively detect antibodies characteristic of diseases such as systemic lupus erythematosus, ${ }^{210}$ the acquired immunodeficiency syndrome (AIDS), ${ }^{211}$ the autism spectrum disorder ${ }^{212}$ and Parkinson's disease (Table 4). ${ }^{213,214}$

But researchers have also developed novel methods varying from staining with secondary antibodies to visualize promising hit compounds. Gao et al. performed surface plasmon

Table 4 Examples of peptoids that bind biomarkers for certain diseases

Disease

Structure

Alzheimer's disease

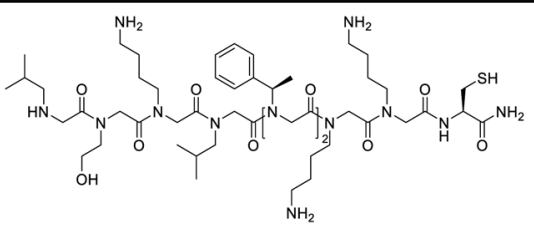

Neuromyelitis optica

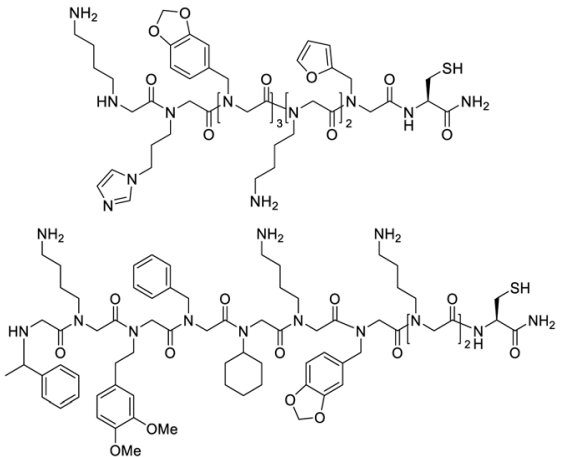

Systemic lupus erythematosus

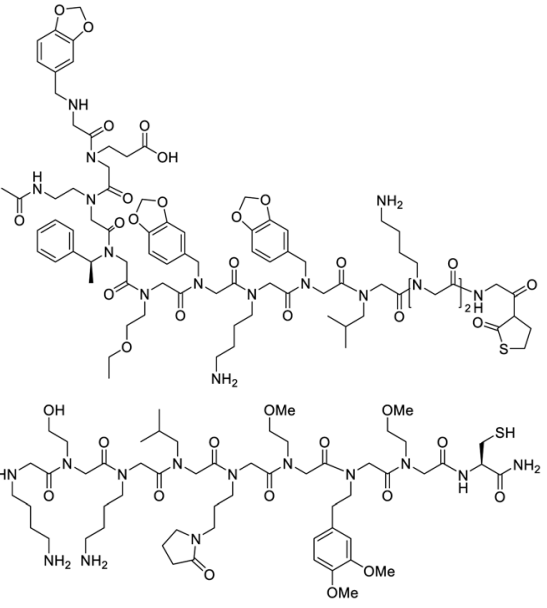

Parkinson's disease 


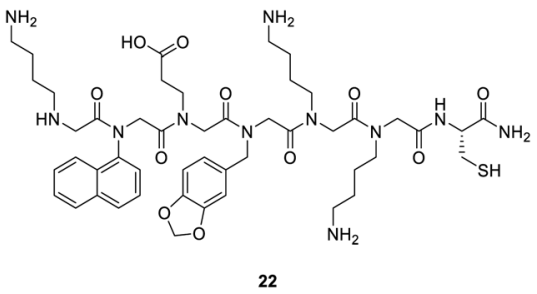

Fig. 15 Peptoid 22 found with the help of surface plasmon resonance imaging of peptoid microarrays serves as a blood-based detection tool for the early-stage diagnosis of Parkinson's disease. ${ }^{215}$

resonance imaging (SPRi, Fig. 14B) to identify $\alpha$-synuclein, a protein that causes neurotoxicity related to Parkinson's disease (PD). A peptoid library of peptidomimetics was synthesized that consisted of a defined C-terminal trimer and a randomized tetramer at the $N$-terminus flanking the overall sequence. A thiol side-chain allowed for the immobilization of the peptoids on a gold chip. The microarray was flushed with $\alpha$-synuclein, and the reflected light changes caused by binding processes were monitored. Kinetic analysis using different concentrations of $\alpha$-synuclein allowed for the identification of the sequence with the highest affinity. The selected peptoid 22 was able to distinguish between healthy individuals and PD patients. Based on these results, a blood-based detection tool for the early-stage diagnosis of PD was discovered and established (Fig. 15). ${ }^{215}$

Udugamasooriya et al. used combinatorial peptoid libraries to search for whole cells as biomarkers. ${ }^{216-218}$ They were able to identify peptoid ligands for antigen-specific autoimmune $\mathrm{T}$ cells, which are known for their role in mediating autoimmune diseases such as multiple sclerosis. An OBOC peptoid library was screened against cells with and without the target receptor. These cells were labeled with red and green quantum dots and afterward screened against different peptoids, each bound to hydrophilic beads. Beads bound to the cells of interest but not to those without the specific receptor were collected, and the peptoids' sequence was identified by Edman degradation. Using this method, the group was able to detect antigen-specific autoimmune $\mathrm{T}$ cells even without knowing the antigen they are directed to. ${ }^{216}$

The method could distinguish between non-small cell lung cancer (NSCLC) stem cells and non-stem cancer cells of the identical tumor line. It was reported that a surface-exposed plectin, a protein usually located inside cells, serves as a potential biomarker for NSCLC. ${ }^{218}$

\section{Combinatorial hit compounds address distinct components of protein complexes and ribonucleic acids}

A reliable regulation of physiological pathways is a key step in the treatment of certain diseases. Peptoids have proved to interact with various, structurally diverse cell components. ${ }^{8,202}$ Already in the first stages of peptoid chemistry, Zuckermann et al. have shown their remarkable potential as high-affinity receptor ligands. Using a combinatorial library of about 5000 peptoid dimers and trimers, they found ligands for two receptors of the $\mathrm{G}$ protein-coupled receptor family. ${ }^{219}$ While most regulators were rationally designed based on natural peptide ligands, ${ }^{220-225}$ some researchers have applied combinatorial peptoid libraries to identify receptor agonists and antagonists capable of modulating cellular signaling pathways using microarray-assisted high-throughput screening methods. ${ }^{26-229}$

Kodadek et al. synthesized an OBOC library to identify regulators of the orexin receptor 1 , a potential target for treating insomnia, diabetes, and drug addiction. They exposed their library to differentially labeled cells with or without the receptor of interest to identify hit compounds. The cell-bound beads were then incubated with specific antibodies and iron oxide particles. A powerful magnet allowed for the extraction and subsequent analysis of promising compounds. ${ }^{228}$ Later, they used a smaller peptoid microarray library to identify moderate up-regulators of orexin signaling. Refinement of the peptoid structures revealed the first small molecule 23 capable of positive allosteric potentiation of the orexin receptor (Fig. 16). ${ }^{227}$

Fu et al., who examined an OBOC library with a theoretical diversity of 106 for agonists of fibroblast growth factor receptors (FGFRs), also applied high-throughput screenings on microarrays. FGFRs are involved in several physiological processes such as the nervous system and embryonic development, angiogenesis, or wound healing. After a fluorescence-based screen and MS/MS sequencing of the hit compounds, potent FGFR agonists with significant impact on the FGFR signaling pathway in different cell lines were discovered (Fig. 17). ${ }^{226}$

While the detection of peptoids binding to cell surface receptors is straightforward, peptoids with intracellular targets must also comprise the capability to cross cellular membranes. Wender and colleagues already detected the first peptoids with cell-penetrating capabilities based on the oligoarginines known from cell-penetrating peptides. ${ }^{230}$ Kodadek et al. used the peptidomimetic approach on OBOCs to identify a peptoid that could translocate into the nucleus and interact with a mammalian coactivator of gene expression. ${ }^{231}$ With another large

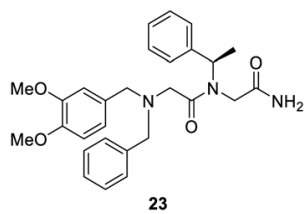

Fig. 16 Peptoid $\mathbf{2 3}$ is the first small molecule that up-regulates orexin signalling. 227

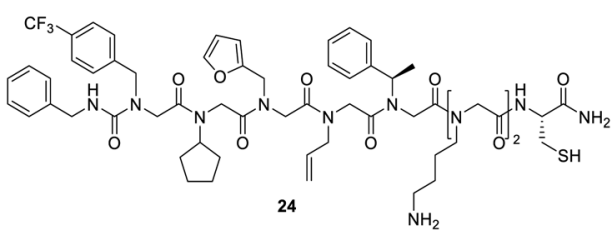

Fig. 17 Peptoid $\mathbf{2 4}$ is one hit sequence of a combinatorial library designed for the search of agonists of FGFRs. ${ }^{226}$ 
OBOC library, they identified a nucleoside-capped peptoid that inhibited the proteasome activity in living cells by interaction with proteasomal ATPases. ${ }^{232}$

Vendrell-Navarro et al. applied a different library format, namely a positional scanning library, to search for apoptosisinducing peptoids. Thus, they synthesized 11638 individual peptoid trimers divided into 68 families characterized by one common amine in a certain position. Initial screens of these 68 mixtures allowed for the isolation of the most promising families. Screening of their sublibraries followed by chemical and biological characterization revealed the type and position of amines crucial for a pro-apoptotic activity. Thus, the working group was able to isolate two peptoid trimers $\mathbf{5}\{\mathbf{3}\} \mathbf{b}$ and $\mathbf{5}\{3\} \mathbf{c}$ that induced apoptosis with a different mechanism of action (Fig. 18). While 5\{3\}b induced apoptosis through the mitochondrial pathway, the group could reduce viability in HeLa cells treated with $5\{3\} \mathbf{c}$ through the induction of mitotic arrest. ${ }^{233}$

In the last decade, the interaction of peptoids with various biological macromolecules has been investigated. Besides the interaction with protein targets, interactions with other classes of macromolecules such as the ribonucleic acids with a high biological impact gain increasing interest. Hamy et al. searched for specific binders of RNA transcripts of the human immunodeficiency virus (HIV). They explicitly looked for a peptoid capable of inhibiting the viral trans-activator protein Tat's binding to the trans-activation-responsive (TAR) element found in HIV transcripts. Thus, they synthesized an OBOC library consisting of four D-amino acids (D-Lys-D-Lys-D-Arg-D-Pro-amide) resembling the natural Tat protein and five variable residues compromised of 20 different building blocks. The group included five D-amino acids to investigate structural features of the backbone towards binding affinity (D-Orn, D-Arg, D-Lys, D-Pro, and D-Phe). NMR measurements of their hit compound 25 revealed a direct bond to the TAR element and thus the first antiviral peptoid that selectively inhibited protein/RNA interaction (Fig. 19). ${ }^{234}$

Several years later, Labuda et al. used combinatorial peptoid microarrays to isolate inhibitors of the group I intron RNA from Candida albicans, a pathogenic yeast fungus that is fatal for immunocompromised patients. Their goal was to inhibit the self-splicing of the group I intron and, thus, to prevent the assembly of active ribosomes. A microarray-based screening of their library followed by further variation and subsequent
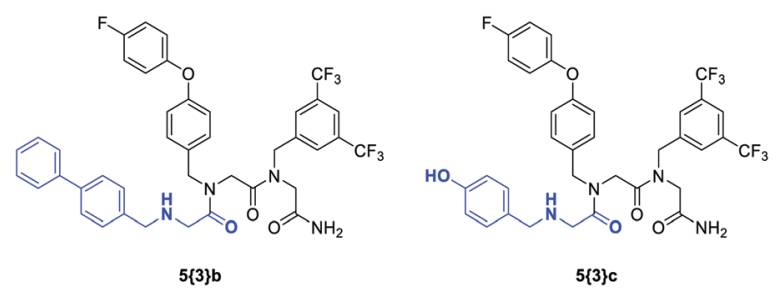

Fig. 18 Peptoid trimers with two different modes of biological activity inducing apoptosis: interference with the mitochondrial pathway (5\{3\}b) and induction of mitotic arrest $(\mathbf{5}\{3\} \mathbf{c})$. The parts in which the peptoids differ are highlighted in blue. ${ }^{233}$

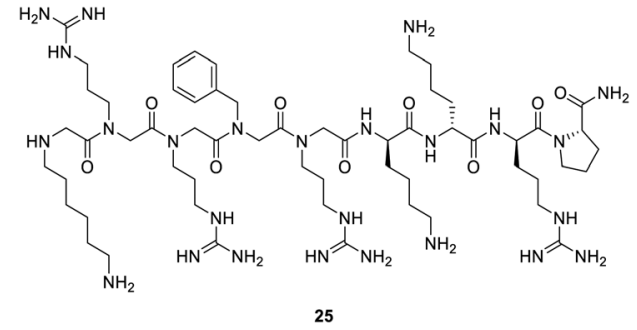

Fig. 19 Peptoid-peptide hybrid 25 showed high TAR RNA affinity. ${ }^{234}$

screening of initial hit compounds resulted in the identification of two peptoids $(\mathbf{5}\{\mathbf{4}\} \mathbf{a}$ and $\mathbf{5}\{\mathbf{4}\} \mathbf{b})$ with the ability to inhibit self-splicing and finally in the design of the peptoid $\mathbf{5}\{\mathbf{5}\} \mathbf{b}$ (Fig. 20) with a biological activity that even exceeded one of the respective, clinically used drugs. ${ }^{235}$

\section{Peptoid-based molecular transporters}

The benefit of molecular transporters is nowadays undisputed. In particular, cell-penetrating peptides and their mimetics have been a research topic for more than two decades. ${ }^{201,236}$ Especially the resistance against proteolytic degradation has made peptoid-based transporters a desirable target for research. ${ }^{7,75,230}$ Kwon and Kodadek developed a high-throughput method to compare the relative cell permeability of peptides with their mimetics and thus laid the foundation to investigate further structure-function relationships of peptoid transporters by screening combinatorial libraries. ${ }^{236}$

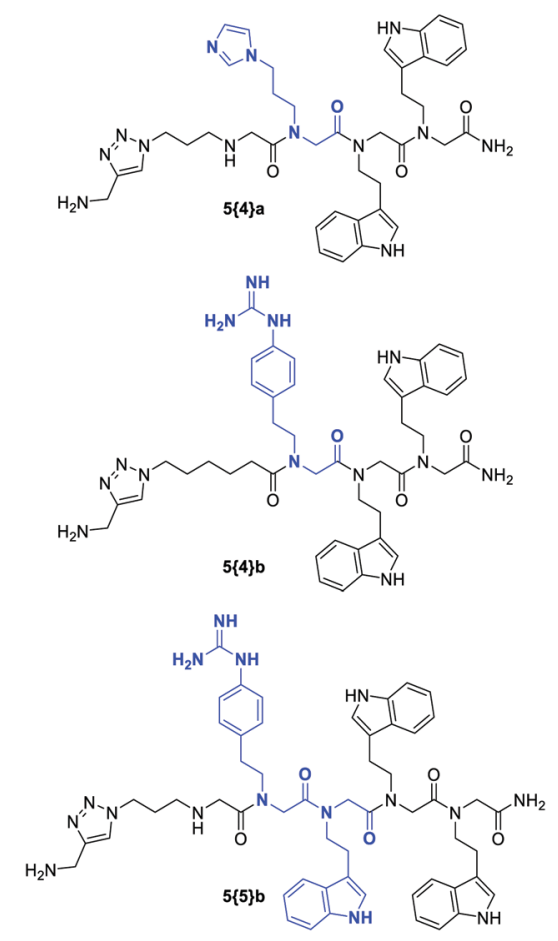

Fig. 20 initial hit compounds $\mathbf{5}\{\mathbf{4}\}$ a and $\mathbf{5}\{\mathbf{4}\}$ b identified in a microarraybased screening and the designed peptoid $\mathbf{5}\{\mathbf{5}\} \mathbf{b}$. The parts in which the peptoids differ are highlighted in blue. ${ }^{235}$ 
Compared to their cell-penetrating peptide counterparts, peptoids with cationic amphiphilic structures showed increased cellular uptake. ${ }^{230,237}$ Small libraries of peptoids with different chain lengths, charges, and hydrophobicity were synthesized by applying the two-step submonomer method, which led to identifying cell-penetrating peptoids that resemble the same uptake mechanism as known from previously reported polyguanidine structures (Fig. 21). ${ }^{238}$

Kölmel et al. established the submonomer-based solidphase synthesis in IRORI MiniKans by synthesizing a proofof-principle combinatorial library of tetrameric peptoids. This approach allowed the automation of the synthesis. By colocalizing the peptoids with the mitochondrial marker MitotrackerGreen $^{\mathrm{TM}}$ when incubating HeLa cells, they found that the interplay between charge and lipophilicity had a major impact on the intracellular localization of the peptoids. Localization in mitochondria, for example, only occurred when a minimum threshold of lipophilicity was reached, whereas a strong positive charge of +3 caused localization in the endosomal compartment. $^{75}$

The Bräse group thoroughly investigated the influence of the cationic and amphiphilic side-chains on their transporter properties. $^{38,239}$ Based on an alkyne-containing backbone, they introduced different side-chains into the sequence via a coppermediated cycloaddition, thus reducing the need for protecting groups during synthesis. ${ }^{239}$ Combined with introducing new side-chains such as polyamines, aza-crown ethers, and triphenylphosphonium ions, the diversity of cell-penetrating peptoids towards their subcellular localization was increased. Especially a highly polar structure was stated fundamental for escaping the endosomal entrapment. ${ }^{38}$

In recent years, the cyclization of peptoids to further enhance their cellular uptake has gained increasing attention. Shin et al. demonstrated that cyclic peptoids showed significantly better uptake than their linear variants, regardless of their size and side-chains. They synthesized a 116000membered combinatorial library of fluorophore-labeled triazine-bridged cyclic peptoids and their corresponding linear counterparts. Evaluation of the cellular uptake was performed by FACS analysis and confocal fluorescence microscopy. They hypothesized that the improved uptake was partially due to the restricted flexibility of the cyclic peptoids (Fig. 22). ${ }^{240}$
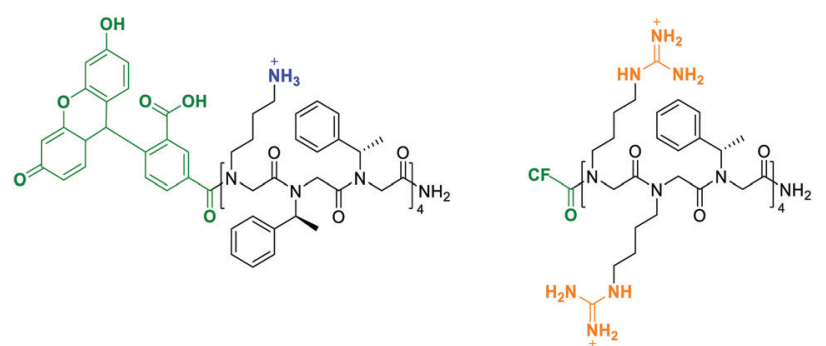

Fig. 21 Examples for cell-penetrating peptoids with positive charges caused by amino (blue) or guanidinium (orange) side-chains. The intracellular location was monitored with the fluorescent dye carboxyfluorescein (CF, green). ${ }^{238}$

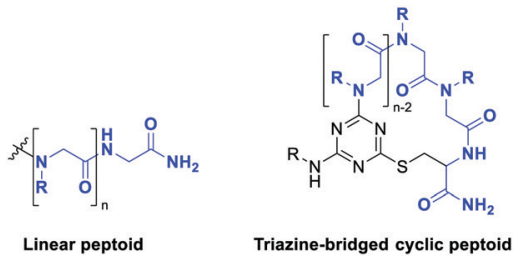

Fig. 22 Comparison of the structure of linear and cyclic peptoids, showing the structural rigidity and conformational restriction of cyclic peptoids. $^{240}$

Kim et al. reported the synthesis and biological evaluation of a novel class of molecular transporters: cell-penetrating, amphiphilic cyclic peptoids. They synthesized a library of cyclic peptoids and identified a transporter candidate with an energydependent endosomal uptake mechanism that showed mainly mitochondrial accumulation. In a further step, they investigated to what extent this amphipathic cyclic octapeptoid can serve as a transporter for drug targeting and found that the novel peptoid is superior to known polyarginine-based molecular transporters. With the stability against proteolytic degradation and the ease of synthesizing the peptoid, this strategy is promising for further development. ${ }^{241}$

Recently, Herlan et al. synthesized a selection of tetrameric and hexameric macrocyclic peptide-peptoid hybrids coupled to the fluorophore rhodamine B using solid and solution phase methods. They found their compounds localizing in mitochondria without including additional cationic charges in the sidechains (Fig. 23). With the solubility of the hybrids in an aqueous environment in mind, this strategy provides a good starting point for further optimization and use as organellespecific transporters. ${ }^{30}$

\section{Peptoids and peptoid-hybrids with antimicrobial activity}

With increasing progress in drug development and clinical treatment methods, antimicrobial resistance has become one major focus of current research. Small molecules that circumvent the defense strategies of multi-resistant bacteria are constantly needed. Antimicrobiological peptides and peptidomimetics such as peptoids thereby represent an alternative to conventional antibiotics. ${ }^{242}$

Towards the end of the 20th century, Goodson et al. were able to identify several trimeric peptoids with antimicrobial activity against Gram-positive and Gram-negative bacteria from an 845-membered combinatorial library built up with 31
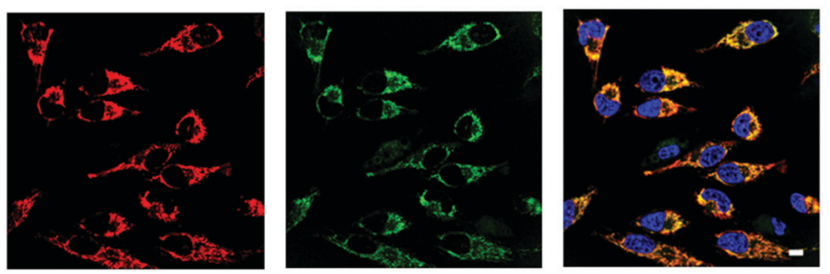

Fig. 23 Mitochondrial localization of an exemplary cell-penetrating peptoid. Left: Fluorescence of the conjugated dye rhodamine B. Middle: Fluorescence of the mitochondrial marker Mitotracker Green ${ }^{\mathrm{TM}}$. Right: Overlay. Scale bar: $10 \mu \mathrm{m}$. $^{30}$ 
different amine building blocks (Table 5). By doing so, they found dehydroabietylamine a recurring component in many active tripeptoids. Deconvolution via positional scanning revealed the best candidate that showed MIC values from $5 \mu \mathrm{M}$ to $40 \mu \mathrm{M}$ against different bacterial strains with moderate hemolytic activity. Eventually, the group was able to demonstrate for the first time the potential of peptoids as antimicrobial agents. ${ }^{243,244}$

In a similar approach, Humet et al. tested an unbiased positional scanning combinatorial library of 3-mer peptoids with over 10000 members for antimicrobial activity against Gram-positive and Gram-negative bacteria. Out of a set of 22 different primary amines, a primary hit with moderate selectivity was found. A subsequent one-point amine substitution increased the antimicrobial activity of the most promising candidate by one order of magnitude. ${ }^{81}$ Later, Patch et al. showed that a minimum chain length of 12 peptoid residues was required to obtain a sufficient antimicrobial effect. ${ }^{245}$ However, the statement was refuted several years later when

Table 5 Amines used for the synthesis of novel peptoid-based antibiotics. The side-chains of the most potent tripeptoid are highlighted in blue $\mathrm{e}^{243}$

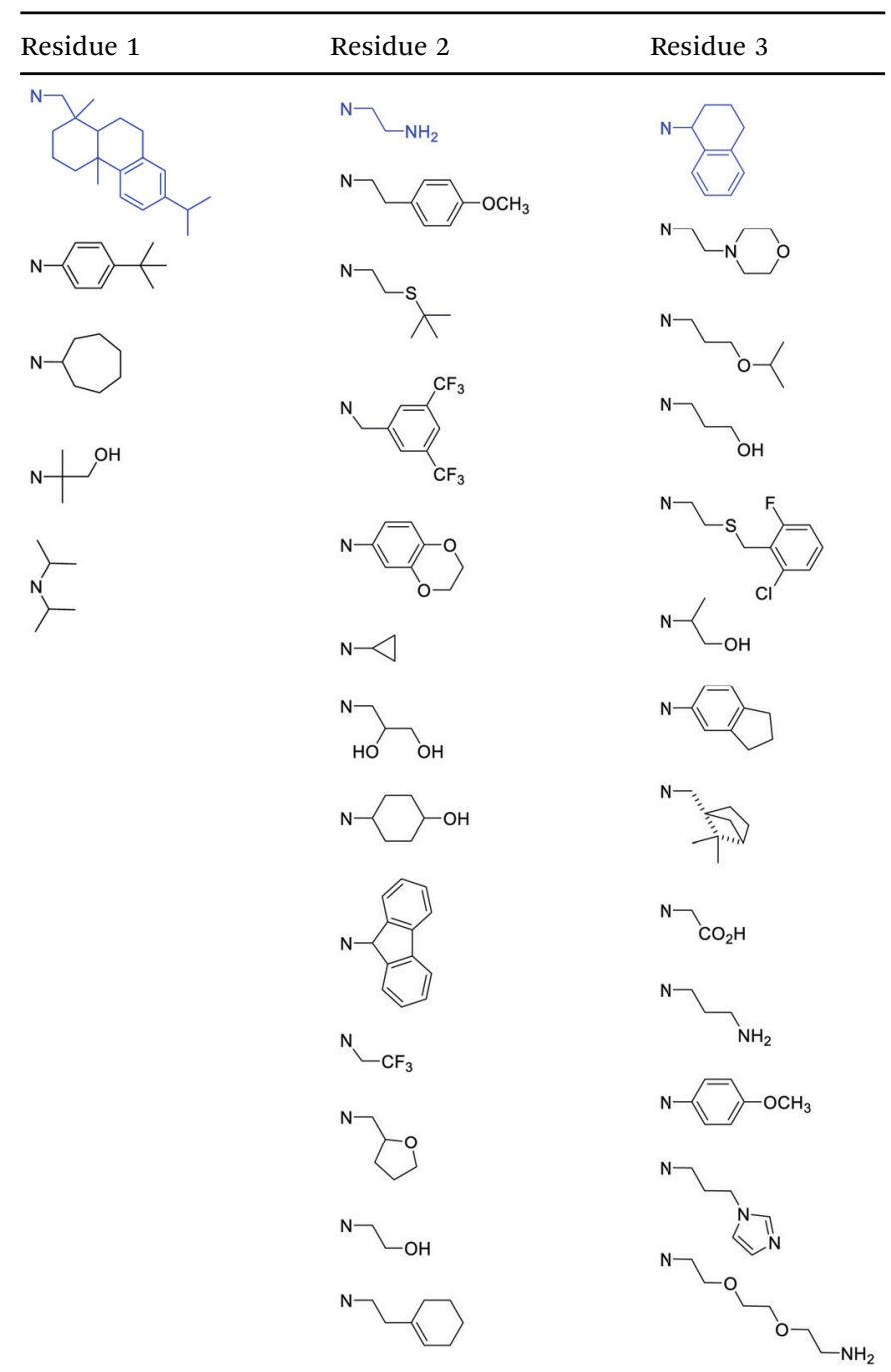

very short, highly potent antimicrobial peptoids were identified. ${ }^{246-248}$

Ryge et al. demonstrated the antimicrobial activity against the Gram-positive Staphylococcus aureus ATCC 25923 and the Gram-negative Escherichia coli ATCC 25922 of several peptoidlysine hybrids. The hemolytic activity against human erythrocytes correlated with the number of lysine residues present in the hybrids. ${ }^{249}$ In subsequent combinatorial studies, the working group identified the most potent amine residues for each position in the peptoid sequence. One compound in particular, hybrid 26, showed high antibacterial activity against $S$. aureus ATCC $25923(\mathrm{MIC}=0.78-1.56 \mu \mathrm{M})$ and $E$. coli ATCC 25922 $(\mathrm{MIC}=1.56-3.13 \mu \mathrm{M})$ with a low hemolytic activity of $7 \%$ (Fig. 24 ). ${ }^{250}$

Based on the astonishing results using peptoid-lysine hybrid structures, Ryge et al. reported several derivatives with antimicrobial activity against various clinically relevant bacterial strains and fungi such as methicillin-resistant Staphylococcus aureus ATC 33591, clinical isolated Salmonella typhimurium, and amphotericin-B-resistant Candida albicans ATCC 200955, among others. For each susceptible strain, they identified at least four hybrids with antimicrobial activity, demonstrating that peptoid-lysine hybrids are a potential solution in the fight against drug-resistant pathogens (Fig. 25). ${ }^{251}$

In the following years, great efforts have been made to understand better the relationship between the structure and function of antimicrobial peptoids. Bolt et al. investigated the relationship between antibacterial activity and toxicity and thereby confirmed, among other things, that with a chain length of 12 or more amine residues, the best antimicrobial activities were achieved. Furthermore, the substitution of certain side-chain protons with fluorine enhanced the activity of the resulting peptoids. ${ }^{252}$ The beneficial effects of chain length and fluorination pattern were also reported by Molchanova et al. They found that an alternating hydrophobic/cationic design was the superior distribution pattern in the biologically active peptoid sequences. ${ }^{253}$ Furthermore, the group was able to establish a correlation between the biological effect of the halogenation and the relative hydrophobicity of the compounds, as well as their self-assembly properties. ${ }^{254}$

The lipophilicity of peptoid oligomers greatly affects antimicrobial activity. By screening a peptoid library against several bacterial strains using a peptoid library agar diffusion (PLAD) assay, Turkett and Bicker established a basis for future designs of peptoid libraries. They, for example, investigated in detail the effect of adding alkyl residues to the peptoid chain. ${ }^{255}$

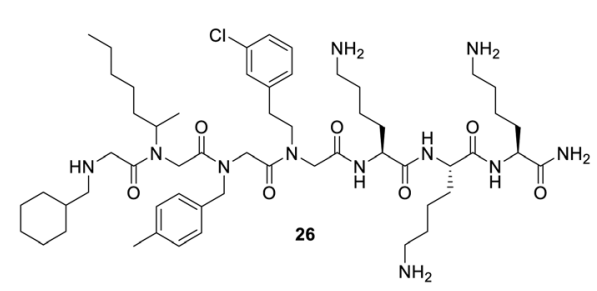

Fig. 24 The antimicrobial peptoid-lysine hybrid $\mathbf{2 6}$ with high antibacterial activity against Gram-positive and Gram-negative bacterial strains. 

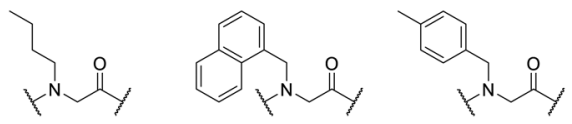

Fig. 25 Amine building blocks used by Ryge et al. to synthesize antimicrobial active peptoid-lysine hybrids with a chain length between five and ten building blocks. ${ }^{251}$

Recent research regarding the structure-function relationship of cationic hydrophobic peptide-peptoid hybrids by Frederiksen et al. led to the hypothesis that two thresholds of hydrophobicity exist for peptidomimetics and their antimicrobial activity: a minimum level of hydrophobicity is required to achieve the antibacterial activity, but selectivity against Gramnegative and Gram-positive cells is lost if the number of hydrophobic moieties is too high. ${ }^{256,257}$

As multi-drug resistant germs pose a major threat for every life on earth, potential drug candidates that substitute common antibiotics are increasingly in demand. Based on previous studies, Khara et al. identified peptoid 27 that showed selective activity against both drug-sensitive and multi-drug resistant Mycobacterium tuberculosis, a pathogen that causes the pulmonary disease tuberculosis (Fig. 26).

Using structure-activity-relationship studies, the group was able to modulate the selectivity of $\mathbf{2 7}$ towards bacterial membranes. Investigating a possible activation of macrophages, the group was able to determine the inability of the mycobacteria to produce NO. They concluded that peptoid 27 does not modulate the immune response but instead interacts directly with the bacterial membrane causing its disruption and subsequent bactericidal. With the help of flow cytometry and time-lapse fluorescence microscopy, the working group could confirm this theory. ${ }^{246}$

Vestergaard et al. reported peptide/ $\beta$-peptoid hybrids with activity against vancomycin-resistant Enterococcus. These pathogens cause several diseases, such as urinary tract infections or meningitis. They screened 20 compounds and further investigated the antibacterial activity of 11 selected candidates against E. faecium and E. faecalis. Two promising leads showed high killing rates on both strains while still being moderate hemolytic (Fig. 27). ${ }^{258}$

At the beginning of the year 2020, humankind faced a challenge whose extent no one could foresee at the time. The COVID-19 pandemic required quick and efficient research in the field of vaccines and new antiviral treatment options. Diamond et al. investigated the antiviral activity of several

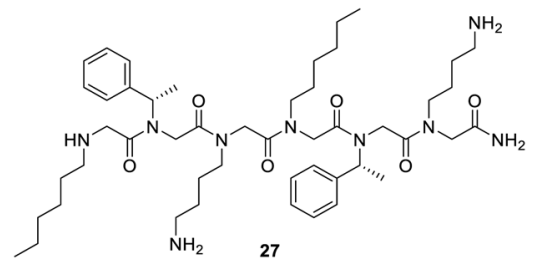

Fig. 26 Peptoid $\mathbf{2 7}$ showed selective activity against Mycobacterium tuberculosis. ${ }^{246}$

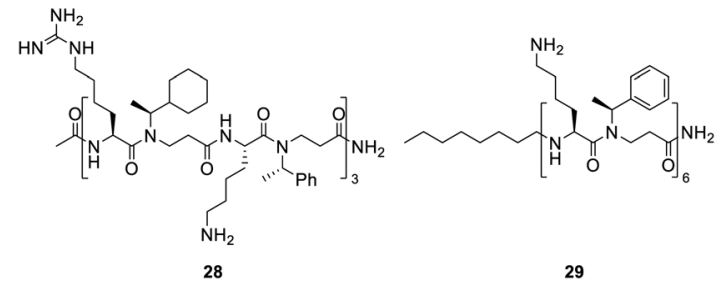

Fig. 27 Peptide/ß-peptoid hybrids with antimicrobial activity against $E$. faecium and E. faecalis. ${ }^{258}$

peptoids and identified compounds with activity against the Herpes Simplex Virus-1 (HSV-1) and the pathogen of COVID-19, SARS-CoV-2. They observed a direct action presumably by damage to the viral envelope and thus a membranedependent mechanism in the treatment of HSV-1. In contrast to the treatment of SARS-CoV-2, this mechanism has not yet been fully elucidated. Looking at the mode of action of a peptide that binds the spike protein of SARS-CoV-2, they assumed a similar mechanism for binding their peptoid instead of a direct interaction with the virus membrane. The authors reported the potential use of peptoids as broadspectrum antivirals to target even highly pathogenic viruses. $^{259}$

\section{Peptoids as therapeutic in cancer treatment and other diseases}

Cancer is inextricably linked to drug discovery as one of the diseases with the highest number of fatalities worldwide. The number of cancer patients is continuing to rise year after year, fueled by, among other things, increasing life expectancy and unhealthy lifestyles in primarily industrialized nations and emerging countries. However, the number of new cancer cases worldwide is estimated at around 19.3 million (2020). According to current expectations, this trend will continue, and even a significant increase is expected. ${ }^{260}$ Research into alternative medicines to the prevailing treatment methods thus offers a broad field and will continue to offer many opportunities in the coming years. In particular, peptoids as an approach to drug discovery and cancer treatment are receiving more and more attention and will continue to find many more applications in this area. ${ }^{261}$

Almost 15 years ago, in 2007, Mas-Moruno et al. identified a tripeptoid family with pro-apoptotic activity. Based on these structures, they synthesized two combinatorial libraries of dipeptoids using the submonomer method. After cytotoxicity screening on several different human cancer cell lines, they found an antiproliferative effect of the dipeptoids on human neoplastic cells. ${ }^{262}$

Huang et al. described a combinatorial library of cationic amphipathic peptoids based on the structure of host-defensive peptides. To investigate if the chain length or the lipophilicity influences the activity, they varied the sequence length and composition of the model structure 30 using six different amine monomers (Fig. 28).

In addition, they studied the relationship between hemolytic activity and the chirality of the peptoids and determined a 
A

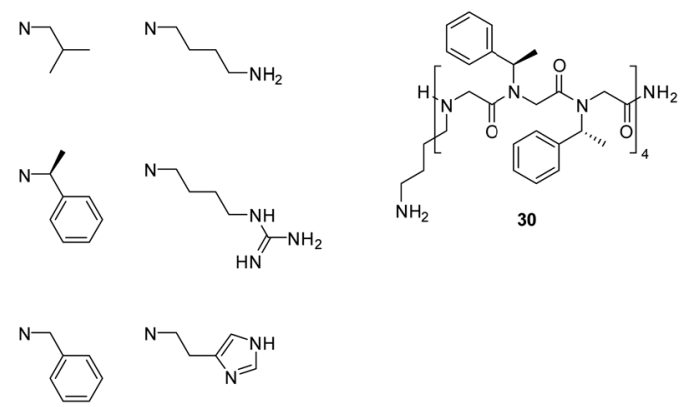

Fig. 28 (A) Amine building blocks used to synthesize a library of cationic, amphiphilic peptoids. (B) Structure of drug candidate $30^{263}$

significantly reduced hemolytic activity when using chiral sidechains. They demonstrated that these peptoids not only exhibited a toxic effect on cancer cell lines but, in some cases, also had modest specificity against them. In addition, they found that the mechanism of action of the peptoids was not influenced by multi-drug resistant effects but occurred mainly due to the disruption of the plasma membrane. The best drug candidate (30) showed significant tumor growth inhibition in mice in the clinically relevant orthotopic xenograft model. Combined with stability against proteolytic degradation, this class of peptoids provides a good starting point for further development as potential cancer therapeutics. ${ }^{263}$

Following the same approach, Lee et al. reported a library of peptide-peptoid hybrid prodrugs selectively activated by prostate cancer cells (Fig. 29). They synthesized 14 different peptoids targeting the prostate-specific antigen (PSA) and prostate-specific membrane antigen (PSMA) and screened them using an MTS assay on PSA/PSMA producing prostate cancer cells.

They found that compounds targeting both antigens were less toxic but seemed to interfere with the selective hydrolysis by PSA. For this reason, they suggested adding a spacer or using other targeting sequences to improve selective hydrolysis in further research efforts. ${ }^{264}$

Further applications of peptoids are described by Schneider et al. in the synthesis of peptide-peptoid macrocycles as inhibitors of $ß$-catenin TCF interaction in prostate cancer cells or Reßing et al. regarding the evaluation of ß-peptoid-capped HDAC inhibitors exhibiting anti-glioblastoma activity. ${ }^{222,265}$

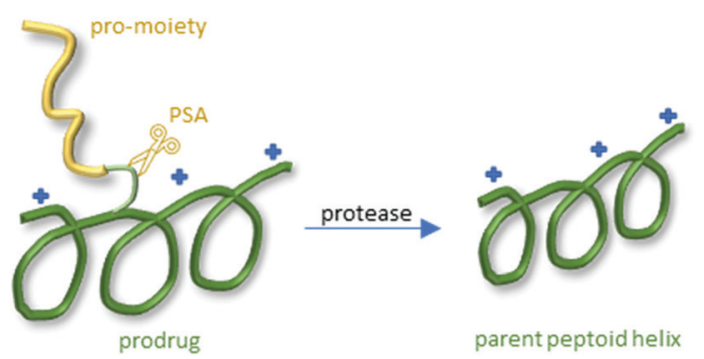

Fig. 29 General procedure of the selective activation of the prodrug into the resulting peptoid. Modified after Lee et al. ${ }^{264}$
Eggiman et al. studied the anti-leishmanial effects of a library of linear peptoids. The synthesized peptoids were screened against Leishmania mexicana, the pathogen that causes the skin disease leishmaniasis. The group was able to identify compounds that showed activity against both promastigotes and axenic amastigotes. As a mechanism of action, they were able to propose that the peptoids studied target the cellular membrane and thus develop their biological activity. $^{266}$

As Wolf et al. stated in their review, peptoids are emerging as potential therapeutics for neurodegenerative diseases such as Alzheimer's, Huntington's, and Parkinson's. Their field of application varies from intervention and modulation of cell signaling pathways by, for example, modulating semaphoring $3 \mathrm{~A}$ to promote axonal regeneration after a CNS injury, ${ }^{267,268}$ to an application as neuroprotective agents or the suppression of neuroinflammation by acting as a tool to amplify a weak immune response or weaken a damaging one. Especially chiral peptoids with restricted conformation are seen as a promising approach. ${ }^{269}$

\section{Conclusions}

In this review, we highlighted the various applications of peptoids and the use of peptoid combinatorial libraries. Particularly in materials science and biological and medical applications, peptoids represent a compound class that enables broad targeting of new research due to their inherent properties such as modular structure, rapid and easy synthesis, coming along with beneficial biological properties such as resistance to proteolytic degradation. Combining the identification via MALDI or NMR with the application of various screening techniques, it is easy to identify hit compounds out of large combinatorial libraries.

Applying peptoids in materials science, three main areas of use can be identified: peptoids as catalysts, metal chelators, and bioinspired materials. Their usefulness spans a broad area in this research field. Peptoids are used as enantioselective catalysts and designed to function as specific metal chelators. Their diversity and physical properties, such as chemical and thermal stability, make them versatile molecules in the entire field of materials science, ranging from sensors to exploiting their ability to form nanosheets and thus application in medical research.

Although peptoids are finding increasing application in materials science, the origin of research on peptoids and combinatorial libraries generated from them lies in medicine and biological applications. To date, this field encompasses much of the research in peptoid chemistry. Combining combinatorial peptoid libraries and screening methods is indispensable in detecting unknown biomarkers and other diseasespecific targets. Current research has already developed tools for medical application in the early diagnosis of Parkinson's disease or as potential cancer therapeutics. Peptoids with 
pro-apoptotic activity have been identified, partially unaffected in their action by multi-drug resistant effects.

The close relationship of peptoids to peptides suggests similar properties with similar structural conditions. For this reason, decades of research in the field of cell-penetrating peptides often serve as a base for developing new peptoids, for example, in their use as molecular transporters. Recent research, especially the cyclization of peptoids, has gained growing attention to improve cellular uptake and obtain highly specific molecular transporters.

Cationic amphipathic peptoids, developed based on cellpenetrating peptides, have long stood out for their antimicrobial properties. They work effectively against Gram-positive and Gram-negative bacteria and show partial activity against resistant and multi-drug resistant bacteria strains. Recent research on antiviral peptoids promises potential efficacy against SARSCoV-2. Further research on this topic is needed to gain a more detailed understanding of antiviral activity and its mechanism.

Given the possibilities and the increase of peptoid research in the last years, we expect a further continuation of this trend and even more promising results for their use in materials science and biomedical applications, driven by the diversity and easy availability of these compounds.

\section{Conflicts of interest}

There are no conflicts to declare.

\section{Acknowledgements}

We acknowledge funding from the cluster 3D Matter Made To Order funded under Germany's Excellence Strategy-2082/ 1-390761711 and the DFG RTG 2039.

\section{References}

1 A. S. Knight, E. Y. Zhou, M. B. Francis and R. N. Zuckermann, Adv. Mater., 2015, 27, 5665-5691.

2 C. Secker, S. M. Brosnan, R. Luxenhofer and H. Schlaad, Macromol. Biosci., 2015, 15, 881-891.

3 J. Sun and R. N. Zuckermann, ACS Nano, 2013, 7, 4715-4732.

4 A. M. Webster and S. L. Cobb, Chemistry, 2018, 24, 7560-7573.

5 S. Xuan and R. N. Zuckermann, Polymer, 2020, 202, 122691.

6 B. Yoo and K. Kirshenbaum, Curr. Opin. Chem. Biol., 2008, 12, 714-721.

7 R. N. Zuckermann, Pept. Sci., 2011, 96, 545-555.

8 R. N. Zuckermann and T. Kodadek, Curr. Opin. Mol. Ther., 2009, 11, 299-307.

9 B. Yoo, S. B. Y. Shin, M. L. Huang and K. Kirshenbaum, Chem. Eur. J., 2010, 16, 5528-5537.

10 K. Kirshenbaum and R. N. Zuckermann, Biopolymers, 2019, 110, e23314.

11 F. De Riccardis, Eur. J. Org. Chem., 2020, 2981-2994.

12 G. L. Butterfoss, P. D. Renfrew, B. Kuhlman, K. Kirshenbaum and R. Bonneau, J. Am. Chem. Soc., 2009, 131, 16798-16807.

13 N. H. Shah, G. L. Butterfoss, K. Nguyen, B. Yoo, R. Bonneau, D. L. Rabenstein and K. Kirshenbaum, J. Am. Chem. Soc., 2008, 130, 16622-16632.

14 A. W. Wijaya, A. I. Nguyen, L. T. Roe, G. L. Butterfoss, R. K. Spencer, N. K. Li and R. N. Zuckermann, J. Am. Chem. Soc., 2019, 141, 19436-19447.
15 C. Caumes, O. Roy, S. Faure and C. Taillefumier, J. Am. Chem. Soc., 2012, 134, 9553-9556.

16 O. Roy, C. Caumes, Y. Esvan, C. Didierjean, S. Faure and C. Taillefumier, Org. Lett., 2013, 15, 2246-2249.

17 J. R. Stringer, J. A. Crapster, I. A. Guzei and H. E. Blackwell, J. Org. Chem., 2010, 75, 6068-6078.

18 Q. Sui, D. Borchardt and D. L. Rabenstein, J. Am. Chem. Soc., 2007, 129, 12042-12048.

19 B. C. Gorske, B. L. Bastian, G. D. Geske and H. E. Blackwell, J. Am. Chem. Soc., 2007, 129, 8928-8929.

20 P. Armand, K. Kirshenbaum, A. Falicov, R. L. Dunbrack, K. A. Dill, R. N. Zuckermann and F. E. Cohen, Folding Des., 1997, 2, 369-375.

21 T. S. Burkoth, E. Beausoleil, S. Kaur, D. Tang, F. E. Cohen and R. N. Zuckermann, Chem. Biol., 2002, 9, 647-654.

22 N. P. Chongsiriwatana, J. A. Patch, A. M. Czyzewski, M. T. Dohm, A. Ivankin, D. Gidalevitz, R. N. Zuckermann and A. E. Barron, Proc. Natl. Acad. Sci. U. S. A., 2008, 105, 2794-2799.

23 D. Gimenez, J. A. Aguilar, E. H. C. Bromley and S. L. Cobb, Angew. Chem., Int. Ed., 2018, 57, 10549-10553.

24 T. J. Sanborn, C. W. Wu, R. N. Zuckermann and A. E. Barron, Biopolymers, 2002, 63, 12-20.

25 C. W. Wu, T. J. Sanborn, K. Huang, R. N. Zuckermann and A. E. Barron, J. Am. Chem. Soc., 2001, 123, 6778-6784.

26 R. V. Mannige, T. K. Haxton, C. Proulx, E. J. Robertson, A. Battigelli, G. L. Butterfoss, R. N. Zuckermann and S. Whitelam, Nature, 2015, 526, 415-420.

27 H. Tran, S. L. Gael, M. D. Connolly and R. N. Zuckermann, J. Vis. Exp., 2011, e3373.

28 J. H. Kim, S. C. Kim, M. A. Kline, E. M. Grzincic, B. W. Tresca, J. Cardiel, M. Karbaschi, D. C. Dehigaspitiya, Y. Chen, V. Udumula, T. Jian, D. J. Murray, L. Yun, M. D. Connolly, J. Liu, G. Ren, C.-L. Chen, K. Kirshenbaum, A. R. Abate and R. N. Zuckermann, ACS Nano, 2020, 14, 185-195.

29 K. T. Nam, S. A. Shelby, P. H. Choi, A. B. Marciel, R. Chen, L. Tan, T. K. Chu, R. A. Mesch, B.-C. Lee, M. D. Connolly, C. Kisielowski and R. N. Zuckermann, Nat. Mater., 2010, 9, 454-460.

30 C. N. Herlan, K. Sommer, P. Weis, M. Nieger and S. Bräse, Molecules, 2021, 26, 150-167.

31 S. B. Vollrath, S. Bräse and K. Kirshenbaum, Chem. Sci., 2012, 3, 2726-2731.

32 S. B. Vollrath, C. Hu, S. Bräse and K. Kirshenbaum, Chem. Commun., 2013, 49, 2317-2319.

33 R. B. Merrifield, J. Am. Chem. Soc., 1963, 85, 2149-2154.

34 R. N. Zuckermann, J. M. Kerr, S. B. H. Kent and W. H. Moos, J. Am. Chem. Soc., 1992, 114, 10646-10647.

35 T. S. Burkoth, A. T. Fafarman, D. H. Charych, M. D. Connolly and R. N. Zuckermann, J. Am. Chem. Soc., 2003, 125, 8841-8845.

36 A. S. Culf and R. J. Ouellette, Molecules, 2010, 15, 5282-5335.

37 C. Cardenal, S. B. Vollrath, U. Schepers and S. Bräse, Helv. Chim. Acta, 2012, 95, 2237-2248.

38 D. K. Kölmel, A. Hörner, F. Rönicke, M. Nieger, U. Schepers and S. Bräse, Eur. J. Med. Chem., 2014, 79, 231-243.

39 D. Fürniss, T. Mack, F. Hahn, S. B. Vollrath, K. Koroniak, U. Schepers and S. Bräse, Beilstein J. Org. Chem., 2013, 9, 56-63.

40 A. Aditya and T. Kodadek, ACS Comb. Sci., 2012, 14, 164-169.

41 S. Vézina-Dawod, A. Derson and E. Biron, Tetrahedron Lett., 2015, 56, 382-385.

42 D. Gimenez, G. Zhou, M. F. D. Hurley, J. A. Aguilar, V. A. Voelz and S. L. Cobb, J. Am. Chem. Soc., 2019, 141, 3430-3434.

43 E. Cini, C. B. Botta, M. Rodriquez and M. Taddei, Tetrahedron Lett., 2009, 50, 7159-7161.

44 A. C. Schneider, D. Fritz, J. K. Vasquez, S. B. Vollrath, H. E. Blackwell and S. Bräse, ACS Comb. Sci., 2017, 19, 715-737.

45 J. Seo, N. Michaelian, S. C. Owens, S. T. Dashner, A. J. Wong, A. E. Barron and M. R. Carrasco, Org. Lett., 2009, 11, 5210-5213.

46 M. A. Fara, J. J. Díaz-Mochón and M. Bradley, Tetrahedron Lett., 2006, 47, 1011-1014.

47 H. J. Olivos, P. G. Alluri, M. M. Reddy, D. Salony and T. Kodadek, Org. Lett., 2002, 4, 4057-4059.

48 M. Goodman and M. Fried, J. Am. Chem. Soc., 1967, 89, 1264-1267.

49 M. Sisido, Y. Imanishi and T. Higashimura, Macromol. Chem. Phys., 1977, 178, 3107-3114.

50 C. Fetsch and R. Luxenhofer, Macromol. Rapid Commun., 2012, 33, 1708-1713. 
51 S. H. Lahasky, W. K. Serem, L. Guo, J. C. Garno and D. Zhang, Macromolecules, 2011, 44, 9063-9074.

52 H. Jin, T. Jian, Y. H. Ding, Y. Chen, P. Mu, L. Wang and C. L. Chen, Biopolymers, 2019, 110, e23258.

53 L. Guo and D. Zhang, J. Am. Chem. Soc., 2009, 131, 18072-18074.

54 D. Zhang, S. H. Lahasky, L. Guo, C.-U. Lee and M. Lavan, Macromolecules, 2012, 45, 5833-5841.

55 N. Gangloff, C. Fetsch and R. Luxenhofer, Macromol. Rapid Commun., 2013, 34, 997-1001.

56 N. Gangloff, J. Ulbricht, T. Lorson, H. Schlaad and R. Luxenhofer, Chem. Rev., 2016, 116, 1753-1802.

57 X. Tao, C. Deng and J. Ling, Macromol. Rapid Commun., 2014, 35, $875-881$.

58 X. Tao, Y. Deng, Z. Shen and J. Ling, Macromolecules, 2014, 47, 6173-6180.

59 L. Guo, S. H. Lahasky, K. Ghale and D. Zhang, J. Am. Chem. Soc., 2012, 134, 9163-9171.

60 C.-U. Lee, T. P. Smart, L. Guo, T. H. Epps III and D. Zhang, Macromolecules, 2011, 44, 9574-9585.

61 P. Salas-Ambrosio, A. Tronnet, M. Since, S. Bourgeade-Delmas, J.-L. Stigliani, A. Vax, S. Lecommandoux, B. Dupuy, P. Verhaeghe and C. Bonduelle, J. Am. Chem. Soc., 2021, 143, 3697-3702.

62 Y. Tao, Z. Wang and Y. Tao, Biopolymers, 2019, 110, e23288.

63 Y. Zhu and Y. Tao, Polym. Chem., 2021, 12, 4895-4902.

64 S. Wang, Y. Tao, J. Wang, Y. Tao and X. Wang, Chem. Sci., 2019, 10, 1531-1538.

65 M. Hartweg, C. J. Edwards-Gayle, E. Radvar, D. Collis, M. Reza, M. Kaupp, J. Steinkoenig, J. Ruokolainen, R. Rambo and C. BarnerKowollik, Polym. Chem., 2018, 9, 482-489.

66 Y. Tao, S. Wang, X. Zhang, Z. Wang, Y. Tao and X. Wang, Biomacromolecules, 2018, 19, 936-942.

67 A. Al Samad, J. De Winter, P. Gerbaux, C. Jérôme and A. Debuigne, Chem. Commun., 2017, 53, 12240-12243.

68 P. Stiernet, B. Couturaud, V. Bertrand, G. Eppe, J. De Winter and A. Debuigne, Polym. Chem., 2021, 12, 2141-2151.

69 R. Liu, X. Li and K. S. Lam, Curr. Opin. Chem. Biol., 2017, 38, 117-126.

70 G. Naseri and M. A. Koffas, Nat. Commun., 2020, 11, 1-14.

71 R. Potyrailo, K. Rajan, K. Stoewe, I. Takeuchi, B. Chisholm and H. Lam, ACS Comb. Sci., 2011, 13, 579-633.

72 R. E. Dolle, B. Le Bourdonnec, G. A. Morales, K. J. Moriarty and J. M. Salvino, J. Comb. Chem., 2006, 8, 597-635.

73 L. Weber, QSAR Comb. Sci., 2005, 24, 809-823.

74 K. S. Lam, M. Lebl and V. Krchňák, Chem. Rev., 1997, 97, 411-448.

75 D. K. Kölmel, D. Fürniss, S. Susanto, A. Lauer, C. Grabher, S. Bräse and U. Schepers, Pharmaceuticals, 2012, 5, 1265-1281.

76 J. Singh, D. Lopes and D. Gomika Udugamasooriya, Peptide Sci., 2016, 106, 673-684.

77 Y. Gao, S. Amar, S. Pahwa, G. Fields and T. Kodadek, ACS Comb. Sci., 2015, 17, 49-59.

78 X. Y. Xiao, R. Li, H. Zhuang, B. Ewing, K. Karunaratne, J. Lillig, R. Brown and K. Nicolaou, Biotechnol. Bioeng., 2000, 71, 44-50.

79 V. V. Komnatnyy, T. E. Nielsen and K. Qvortrup, Chem. Commun., 2018, 54, 6759-6771.

80 P. G. Alluri, M. M. Reddy, K. Bachhawat-Sikder, H. J. Olivos and T. Kodadek, J. Am. Chem. Soc., 2003, 125, 13995-14004.

81 M. Humet, T. Carbonell, I. Masip, F. Sánchez-Baeza, P. Mora, E. Cantón, M. Gobernado, C. Abad, E. Pérez-Payá and A. Messeguer, J. Comb. Chem., 2003, 5, 597-605.

82 I. Masip, N. Cortés, M.-J. Abad, M. Guardiola, E. Pérez-Payá, J. Ferragut, A. Ferrer-Montiel and A. Messeguer, Bioorg. Med. Chem., 2005, 13, 1923-1929.

83 N. Heine, T. Ast, J. Schneider-Mergener, U. Reineke, L. Germeroth and H. Wenschuh, Tetrahedron, 2003, 59, 9919-9930.

84 R. Frank, Tetrahedron, 1992, 48, 9217-9232.

85 R. Frank, J. Immunol. Methods, 2002, 267, 13-26.

86 Y.-U. Kwon and T. Kodadek, Chem. Commun., 2008, 5704-5706.

87 M. M. Reddy and T. Kodadek, Proc. Natl. Acad. Sci. U. S. A., 2005, 102, 12672-12677.

88 R. G. Ireland, M. Kibschull, J. Audet, M. Ezzo, B. Hinz, S. J. Lye and C. A. Simmons, Biomaterials, 2020, 248, 120017.

89 G. MacBeath, J. Am. Chem. Soc., 1999, 121, 7967-7968.

90 P. J. Hergenrother, K. M. Depew and S. L. Schreiber, J. Am. Chem. Soc., 2000, 122, 7849-7850.
$91 \mathrm{~S} . \mathrm{Li}, \mathrm{D}$. Bowerman, N. Marthandan, S. Klyza, K. J. Luebke, H. R. Garner and T. Kodadek, J. Am. Chem. Soc., 2004, 126, 4088-4089.

92 A. Shaginian, M. Patel, M.-H. Li, S. T. Flickinger, C. Kim, F. Cerrina and P. J. Belshaw, J. Am. Chem. Soc., 2004, 126, 16704-16705.

93 F. G. Kuruvilla, A. F. Shamji, S. M. Sternson, P. J. Hergenrother and S. L. Schreiber, Nature, 2002, 416, 653-657.

94 H.-S. Lim, M. Muralidhar Reddy, X. Xiao, J. Wilson, R. Wilson, S. Connell and T. Kodadek, Bioorg. Med. Chem. Lett., 2009, 19, 3866-3869.

95 J. M. Astle, L. S. Simpson, Y. Huang, M. M. Reddy, R. Wilson, S. Connell, J. Wilson and T. Kodadek, Chem. Biol., 2010, 17, 38-45.

96 D. S. Mattes, B. Streit, D. R. Bhandari, J. Greifenstein, T. C. Foertsch, S. W. Münch, B. Ridder, C. V. Bojničić-Kninski, A. Nesterov-Mueller and B. Spengler, Macromol. Rapid Commun., 2019, 40, 1800533

97 B. Yan, Curr. Opin. Chem. Biol., 2002, 6, 328-332.

98 V. Swali and M. Bradley, Anal. Commun., 1997, 34, 15H-18H.

99 I. Hughes and D. Hunter, Curr. Opin. Chem. Biol., 2001, 5, 243-247.

100 A. Boeijen and R. M. Liskamp, Tetrahedron Lett., 1998, 39, 3589-3592.

101 A. Thakkar, A. S. Cohen, M. D. Connolly, R. N. Zuckermann and D. Pei, J. Comb. Chem., 2009, 11, 294-302.

102 C. Enjalbal, J. Martinez and J.-L. Aubagnac, Mass Spectrom. Rev., 2000, 19, 139-161.

103 M. G. Paulick, K. M. Hart, K. M. Brinner, M. Tjandra, D. H. Charych and R. N. Zuckermann, J. Comb. Chem., 2006, 8, 417-426.

104 K. J. Lee and H.-S. Lim, Org. Lett., 2014, 16, 5710-5713.

105 L. S. Simpson and T. Kodadek, Tetrahedron Lett., 2012, 53, 2341-2344.

106 J. HoonáLee, Chem. Commun., 2010, 46, 8615-8617.

107 M. C. Pirrung, K. Park and L. N. Tumey, J. Comb. Chem., 2002, 4, 329-344.

108 M. H. Shin, K. J. Lee and H.-S. Lim, Bioconjugate Chem., 2019, 30, 2931-2938.

109 H. Kang, Y. Koh, S. Jeong, C. Jeong, M. G. Cha, M.-H. Oh, J.-K. Yang, H. Lee, D. H. Jeong, B.-H. Jun, H. Chang, Y.-K. Kim and Y.-S. Lee, Sens. Actuators, B, 2020, 303, 127211.

110 B. C. Gorske, E. M. Mumford, C. G. Gerrity and I. Ko, J. Am. Chem. Soc., 2017, 139, 8070-8073.

111 K. Huang, C. W. Wu, T. J. Sanborn, J. A. Patch, K. Kirshenbaum, R. N. Zuckermann, A. E. Barron and I. Radhakrishnan, J. Am. Chem. Soc., 2006, 128, 1733-1738.

112 J. A. Crapster, I. A. Guzei and H. E. Blackwell, Angew. Chem., Int. Ed., 2013, 52, 5079-5084.

113 B. C. Gorske, E. M. Mumford and R. R. Conry, Org. Lett., 2016, 18, $2780-2783$

114 Y. Luo, Y. Song, M. Wang, T. Jian, S. Ding, P. Mu, Z. Liao, O. Shi, X. Cai, H. Jin, D. Du, W.-J. Dong, C.-L. Chen and Y. Lin, Small, 2019, 15, 1902485.

115 S. H. Gellman, Acc. Chem. Res., 1998, 31, 173-180.

116 P. Armand, K. Kirshenbaum, R. A. Goldsmith, S. Farr-Jones, A. E. Barron, K. T. Truong, K. A. Dill, D. F. Mierke, F. E. Cohen, R. N. Zuckermann and E. K. Bradley, Proc. Natl. Acad. Sci. U. S. A., 1998, 95, 4309-4314.

117 H.-M. Shin, C.-M. Kang, M.-H. Yoon and J. Seo, Chem. Commun., 2014, 50, 4465-4468.

118 C. W. Wu, K. Kirshenbaum, T. J. Sanborn, J. A. Patch, K. Huang, K. A. Dill, R. N. Zuckermann and A. E. Barron, J. Am. Chem. Soc., 2003, 125, 13525-13530.

119 C. W. Wu, T. J. Sanborn, R. N. Zuckermann and A. E. Barron, J. Am. Chem. Soc., 2001, 123, 2958-2963.

120 S. A. Fowler, R. Luechapanichkul and H. E. Blackwell, J. Org. Chem., 2009, 74, 1440-1449.

121 J. R. Stringer, J. A. Crapster, I. A. Guzei and H. E. Blackwell, J. Am. Chem. Soc., 2011, 133, 15559-15567.

$122 \mathrm{~J}$. Engel-Andreasen, K. Wich, J. S. Laursen, P. Harris and C. A. Olsen, J. Org. Chem., 2015, 80, 5415-5427.

123 J. Seo, A. E. Barron and R. N. Zuckermann, Org. Lett., 2010, 12, 492-495.

124 B. C. Gorske, J. R. Stringer, B. L. Bastian, S. A. Fowler and H. E. Blackwell, J. Am. Chem. Soc., 2009, 131, 16555-16567.

125 J. A. Crapster, J. R. Stringer, I. A. Guzei and H. E. Blackwell, Pept. Sci., 2011, 96, 604-616. 
126 P. A. Jordan, B. Paul, G. L. Butterfoss, P. D. Renfrew, R. Bonneau and K. Kirshenbaum, Pept. Sci., 2011, 96, 617-626.

127 G. L. Butterfoss, B. Yoo, J. N. Jaworski, I. Chorny, K. A. Dill, R. N. Zuckermann, R. Bonneau, K. Kirshenbaum and V. A. Voelz, Proc. Natl. Acad. Sci. U. S. A., 2012, 109, 14320-14325.

128 L. J. Weiser and E. E. Santiso, AIMS Mater. Sci., 2017, 4, 1029-1051.

129 S. A. Fowler and H. E. Blackwell, Org. Biomol. Chem., 2009, 7, 1508-1524.

130 M. Zhao, J. Sampath, S. Alamdari, G. Shen, C.-L. Chen, C. J. Mundy, J. Pfaendtner and A. L. Ferguson, J. Phys. Chem. B, 2020, 124, 7745-7764.

131 P. D. Renfrew, T. W. Craven, G. L. Butterfoss, K. Kirshenbaum and R. Bonneau, J. Am. Chem. Soc., 2014, 136, 8772-8782.

132 A. S. Culf, Biopolymers, 2019, 110, e23285.

133 K. H. AaronáLau, Biomater. Sci., 2014, 2, 627-633.

134 G. R. Marshall and F. Ballante, Drug Dev. Res., 2017, 78, 245-267.

135 T. Ghosh, P. Ghosh and G. Maayan, ACS Catal., 2018, 8, 10631-10640.

136 G. Ruan, L. Engelberg, P. Ghosh and G. Maayan, Chem. Commun., 2021, 57, 939-942.

137 G. Maayan, M. D. Ward and K. Kirshenbaum, Proc. Natl. Acad. Sci. U. S. A., 2009, 106, 13679-13684.

138 C. M. Darapaneni, P. Ghosh, T. Ghosh and G. Maayan, Chem. - Eur. J., 2020, 26, 9573-9579.

139 Y. Stamatin and G. Maayan, Eur. J. Org. Chem., 2020, 3147-3152.

140 R. Schettini, B. Nardone, F. De Riccardis, G. Della Sala and I. Izzo, Eur. J. Org. Chem., 2014, 7793-7797.

141 R. Schettini, F. De Riccardis, G. Della Sala and I. Izzo, J. Org. Chem., 2016, 81, 2494-2505.

142 A. F. de la Torre, D. G. Rivera, M. A. B. Ferreira, A. G. Corrêa and M. W. Paixão, J. Org. Chem., 2013, 78, 10221-10232.

143 M. C. Brauer, R. A. Neves Filho, B. Westermann, R. Heinke and L. A. Wessjohann, Beilstein J. Org. Chem., 2015, 11, 25-30.

144 M. Abbas, J. Bethke and L. A. Wessjohann, Chem. Commun., 2006, 541-543.

145 D. G. Rivera and L. A. Wessjohann, J. Am. Chem. Soc., 2006, 128, $7122-7123$

146 A. S. Knight, E. Y. Zhou, J. G. Pelton and M. B. Francis, J. Am. Chem. Soc., 2013, 135, 17488-17493.

147 B. F. Parker, A. S. Knight, S. Vukovic, J. Arnold and M. B. Francis, Ind. Eng. Chem. Res., 2016, 55, 4187-4194.

148 A. S. Knight, R. U. Kulkarni, E. Y. Zhou, J. M. Franke, E. W. Miller and M. B. Francis, Chem. Commun., 2017, 53, 3477-3480.

149 A. S. Knight, E. Y. Zhou and M. B. Francis, Chem. Sci., 2015, 6, $4042-4048$.

150 P. Ghosh, I. Rozenberg and G. Maayan, J. Inorg. Biochem., 2021, 217, 111388.

151 M. Baskin, L. Panz and G. Maayan, Chem. Commun., 2016, 52, 10350-10353.

152 M. Baskin and G. Maayan, Pept. Sci., 2015, 104, 577-584.

153 P. Ghosh and G. Maayan, Chem. Sci., 2020, 11, 10127-10134.

154 D. M. Nalband, B. P. Warner, N. H. Zahler and K. Kirshenbaum, Pept. Sci., 2014, 102, 407-415.

155 A. Ricano, I. Captain, K. P. Carter, B. P. Nell, G. J.-P. Deblonde and R. J. Abergel, Chem. Sci., 2019, 10, 6834-6843.

156 A. I. Nguyen, R. K. Spencer, C. L. Anderson and R. N. Zuckermann, Chem. Sci., 2018, 9, 8806-8813.

157 R. Napolitano, T. C. Soesbe, L. M. De León-Rodríguez, A. D. Sherry and D. G. Udugamasooriya, J. Am. Chem. Soc., 2011, 133, 13023-13030.

158 J. Singh, V. Rustagi, S. Zhang, A. D. Sherry and D. G. Udugamasooriya, Magn. Reson. Chem., 2017, 55, 747-753.

159 A. Battigelli, J. H. Kim, D. C. Dehigaspitiya, C. Proulx, E. J. Robertson, D. J. Murray, B. Rad, K. Kirshenbaum and R. N. Zuckermann, ACS Nano, 2018, 12, 2455-2465.

160 J. L. Roberts, G. R. Perez Bakovic and S. L. Servoss, Sens. Bio-Sens, 2021, 32, 100424-100430.

161 A. Battigelli, Biopolymers, 2019, 110, e23265.

162 D. J. Murray, J. H. Kim, E. M. Grzincic, S. C. Kim, A. R. Abate and R. N. Zuckermann, Langmuir, 2019, 35, 13671-13680.

163 F. Jiao, Y. Chen, H. Jin, P. He, C. L. Chen and J. J. De Yoreo, Adv. Funct. Mater., 2016, 26, 8960-8967.

164 H. Jin, F. Jiao, M. D. Daily, Y. Chen, F. Yan, Y.-H. Ding, X. Zhang, E. J. Robertson, M. D. Baer and C.-L. Chen, Nat. Commun., 2016, 7, $1-8$.
165 A. R. Statz, R. J. Meagher, A. E. Barron and P. B. Messersmith, J. Am. Chem. Soc., 2005, 127, 7972-7973.

166 W. van Zoelen, H. G. Buss, N. C. Ellebracht, N. A. Lynd, D. A. Fischer, J. Finlay, S. Hill, M. E. Callow, J. A. Callow, E. J. Kramer, R. N. Zuckermann and R. A. Segalman, ACS Macro Lett., 2014, 3, 364-368.

167 C. Leng, H. G. Buss, R. A. Segalman and Z. Chen, Langmuir, 2015, 31, 9306-9311.

168 J. L. Dalsin and P. B. Messersmith, Mater. Today, 2005, 8, 38-46.

169 K. H. A. Lau, C. Ren, T. S. Sileika, S. H. Park, I. Szleifer and P. B. Messersmith, Langmuir, 2012, 28, 16099-16107.

170 M. Monahan, B. Cai, T. Jian, S. Zhang, G. Zhu, C.-L. Chen, J. J. De Yoreo and B. M. Cossairt, Nanoscale, 2021, 13, 1273-1282.

171 F. Yan, L. Liu, T. R. Walsh, Y. Gong, P. Z. El-Khoury, Y. Zhang, Z. Zhu, J. J. De Yoreo, M. H. Engelhard, X. Zhang and C.-L. Chen, Nat. Commun., 2018, 9, 2327.

172 D. B. Robinson, G. M. Buffleben, M. E. Langham and R. N. Zuckermann, Pept. Sci., 2011, 96, 669-678.

173 H. Tigger-Zaborov and G. Maayan, J. Colloid Interface Sci., 2017, 508, 56-64.

174 G. Maayan and L.-K. Liu, Pept. Sci., 2011, 96, 679-687.

175 E. J. Robertson, C. Avanessian, J. R. Davis, A. K. Mahony and E. V. Whitney, Chem. Commun., 2021, 57, 2748-2751.

176 S. Hoyas, O. M. Roscioni, C. Tonneaux, P. Gerbaux, J. Cornil and L. Muccioli, Biomacromolecules, 2021, 22, 2573-2581.

177 H. Reese, T. Bordelon, F. Odeh, A. Broussard, C. Kormos, A. Murphy, C. Shanahan and S. Menegatti, Biotechnol. Prog., 2020, 36, e2994.

178 H. Wu, K. Li, H. Yu, Y. Ke and X. Liang, J. Chromatogr. A, 2013, 1281, 155-159.

179 H. Reese, T. Bordelon, C. Shanahan, M. Crapanzano, J. Sly and S. Menegatti, J. Chromatogr. B: Anal. Technol. Biomed. Life Sci., 2020, 1137, 121909.

180 M. A. Ward and T. K. Georgiou, Polymers, 2011, 3, 1215-1242.

181 A. Bordat, T. Boissenot, J. Nicolas and N. Tsapis, Adv. Drug Delivery Rev., 2019, 138, 167-192.

182 D. Liu and J. Sun, Polymers, 2020, 12, 2973.

183 R. Fang, J. Pi, T. Wei, A. Ali and L. Guo, Polymers, 2021, 13, 2089.

184 H. O. Ham, S. H. Park, J. W. Kurutz, I. G. Szleifer and P. B. Messersmith, J. Am. Chem. Soc., 2013, 135, 13015-13022.

185 A. R. Statz, A. E. Barron and P. B. Messersmith, Soft Matter, 2008, 4, 131-139.

186 A. R. Statz, J. Kuang, C. Ren, A. E. Barron, I. Szleifer and P. B. Messersmith, Biointerphases, 2009, 4, Fa22-Fa32.

187 K. H. A. Lau, T. S. Sileika, S. H. Park, A. M. Sousa, P. Burch, I. Szleifer and P. B. Messersmith, Adv. Mater. Interfaces, 2015, $2,1400225$.

188 J. Y. Ryu, I. T. Song, K. A. Lau, P. B. Messersmith, T.-Y. Yoon and H. Lee, ACS Appl. Mater. Interfaces, 2014, 6, 3553-3558.

189 D. L. Cheung and K. H. A. Lau, Langmuir, 2019, 35, 1483-1494.

190 W. Yang, Q. Yin and C.-L. Chen, Chem. Mater., 2021, 33, 3047-3065.

191 B. Cai, Z. Li and C.-L. Chen, Acc. Chem. Res., 2021, 54, 81-91.

192 R. Li, A. Smolyakova, G. Maayan and J. D. Rimer, Chem. Mater., 2017, 29, 9536-9546.

193 C.-L. Chen, J. Qi, J. Tao, R. N. Zuckermann and J. J. DeYoreo, Sci. Rep., 2014, 4, 6266.

194 C.-L. Chen, J. Qi, R. N. Zuckermann and J. J. DeYoreo, J. Am. Chem. Soc., 2011, 133, 5214-5217.

195 M. L. Huang, D. Ehre, Q. Jiang, C. Hu, K. Kirshenbaum and M. D. Ward, Proc. Natl. Acad. Sci. U. S. A., 2012, 109, 19922-19927.

196 W. Hua, Y. Wang, C.-Y. Guo, J. Wang, S. Li and L. Guo, J. Inorg. Organomet. Polym. Mater., 2021, 31, 203-208.

197 G. K. Olivier, A. Cho, B. Sanii, M. D. Connolly, H. Tran and R. N. Zuckermann, ACS Nano, 2013, 7, 9276-9286.

198 L. Zhu, Z. Zhao, P. Cheng, Z. He, Z. Cheng, J. Peng, H. Wang, C. Wang, Y. Yang and Z. Hu, Adv. Mater., 2017, 29, 1700057.

199 H. Gao, M. Liu, Z. Zhao, C. Yang, L. Zhu, Y. Cai, Y. Yang and Z. Hu, ACS Appl. Mater. Interfaces, 2020, 12, 9693-9700.

200 L. Chio, J. T. Del Bonis-O'Donnell, M. A. Kline, J. H. Kim, I. R. McFarlane, R. N. Zuckermann and M. P. Landry, Nano Lett., 2019, 19, 7563-7572.

201 J. E. Murphy, T. Uno, J. D. Hamer, F. E. Cohen, V. Dwarki and R. N. Zuckermann, Proc. Natl. Acad. Sci. U. S. A., 1998, 95, 1517-1522. 
202 M. T. Dohm, R. Kapoor and A. E. Barron, Curr. Pharm. Des., 2011, 17, 2732-2747.

203 R. J. Simon, R. S. Kania, R. N. Zuckermann, V. D. Huebner, D. A. Jewell, S. Banville, S. Ng, L. Wang, S. Rosenberg and C. K. Marlowe, et al., Proc. Natl. Acad. Sci. U. S. A., 1992, 89, 9367-9371.

204 M. D. Burke and S. L. Schreiber, Angew. Chem., Int. Ed., 2004, 43, 46-58.

205 D. S. Tan, Nat. Chem. Biol., 2005, 1, 74-84.

206 W. R. Galloway, A. Isidro-Llobet and D. R. Spring, Nat. Commun., 2010, 1, 80.

207 M. M. Reddy, R. Wilson, J. Wilson, S. Connell, A. Gocke, L. Hynan, D. German and T. Kodadek, Cell, 2011, 144, 132-142.

208 B. L. Raveendra, H. Wu, R. Baccala, M. M. Reddy, J. Schilke, J. L. Bennett, A. N. Theofilopoulos and T. Kodadek, Chem. Biol., 2013, 20, 351-359.

209 D. Cai, A. Y. Lee, C.-M. Chiang and T. Kodadek, Bioorg: Med. Chem. Lett., 2011, 21, 4960-4964.

210 J. Quan, A. Lakhanpal, M. M. Reddy, S. Zaman, Q.-Z. Li, D. C. German, N. J. Olsen, T. Kodadek and D. R. Karp, J. Immunol. Methods, 2014, 402, 23-34.

211 T. L. Gearhart, R. C. Montelaro, M. E. Schurdak, C. D. Pilcher, C. R. Rinaldo, T. Kodadek, Y. Park, K. Islam, R. Yurko, E. T. A. Marques and D. S. Burke, J. Immunol. Methods, 2016, 435, 85-89.

212 S. Zaman, U. Yazdani, Y. Deng, W. Li, B. S. Gadad, L. Hynan, D. Karp, N. Roatch, C. Schutte, C. Nathan Marti, L. Hewitson and D. C. German, Sci. Rep., 2016, 6, 19164.

213 U. Yazdani, S. Zaman, L. S. Hynan, L. S. Brown, R. B. Dewey, D. Karp and D. C. German, npj Parkinson's Disease, 2016, 2, 16012.

214 N. Feng, S. Simanski, K. Islam, L. S. Hynan, T. Kodadek and D. C. German, npj Parkinson's Disease, 2018, 4, 1-5.

215 H. Gao, Z. Zhao, Z. He, H. Wang, M. Liu, Z. Hu, O. Cheng, Y. Yang and L. Zhu, ACS Chem. Neurosci., 2019, 10, 1204-1208.

216 A. R. Gocke, D. G. Udugamasooriya, C. T. Archer, J. Lee and T. Kodadek, Chem. Biol., 2009, 16, 1133-1139.

217 D. G. Udugamasooriya, S. P. Dineen, R. A. Brekken and T. Kodadek, J. Am. Chem. Soc., 2008, 130, 5744-5752.

218 A. C. Raymond, B. Gao, L. Girard, J. D. Minna and D. G. Udugamasooriya, Sci. Rep., 2019, 9, 1-15.

219 R. N. Zuckermann, E. J. Martin, D. C. Spellmeyer, G. B. Stauber, K. R. Shoemaker, J. M. Kerr, G. M. Figliozzi, D. A. Goff, M. A. Siani and R. J. Simon, J. Med. Chem., 1994, 37, 2678-2685.

220 C. M. Low, J. W. Black, H. B. Broughton, I. M. Buck, J. M. Davies, D. J. Dunstone, R. A. Hull, S. B. Kalindjian, I. M. McDonald and M. J. Pether, J. Med. Chem., 2000, 43, 3505-3517.

221 D. Diedrich, A. Hamacher, C. Gertzen, L. A. Avelar, G. Reiss, T. Kurz, H. Gohlke, M. Kassack and F. Hansen, Chem. Commun., 2016, 52, 3219-3222.

222 J. A. Schneider, T. W. Craven, A. C. Kasper, C. Yun, M. Haugbro, E. M. Briggs, V. Svetlov, E. Nudler, H. Knaut and R. Bonneau, Nat. Commun., 2018, 9, 1-10.

223 J. P. Turner, T. Lutz-Rechtin, K. A. Moore, L. Rogers, O. Bhave, M. A. Moss and S. L. Servoss, ACS Chem. Neurosci., 2014, 5, $552-558$.

224 J. Hughes, G. Dockray, D. Hill, L. Garcia, M. Pritchard, E. Forster, E. Toescu, G. Woodruff and D. Horwell, Regul. Pept., 1996, 65, $15-21$.

225 M. Park, M. Wetzler, T. S. Jardetzky and A. E. Barron, PLoS One, 2013, 8, e58874.

226 J. Fu, A. Xia and X. Qi, MedChemComm, 2016, 7, 1183-1189.

227 J. Lee, M. M. Reddy and T. Kodadek, Chem. Sci., 2010, 1, 48-54.

228 X. Qi, J. Astle and T. Kodadek, Mol. BioSyst., 2010, 6, 102-107.

229 F. Dasgupta, N. Gangadhar, M. Bruhaspathy, A. K. Verma, S. Sarin and A. K. Mukherjee, Bioorg. Med. Chem. Lett., 2001, 11, 555-557.

230 P. A. Wender, D. J. Mitchell, K. Pattabiraman, E. T. Pelkey, L. Steinman and J. B. Rothbard, Proc. Natl. Acad. Sci. U. S. A., 2000, 97, 13003-13008.

231 P. Alluri, B. Liu, P. Yu, X. Xiao and T. Kodadek, Mol. BioSyst., 2006, $2,568-579$.

232 H.-S. Lim, C. T. Archer and T. Kodadek, J. Am. Chem. Soc., 2007, 129, 7750-7751.

233 G. Vendrell-Navarro, F. Rúa, J. Bujons, A. Brockmeyer, P. Janning, S. Ziegler, A. Messeguer and H. Waldmann, ChemBioChem, 2015, 16, 1580-1587.
234 F. Hamy, E. R. Felder, G. Heizmann, J. Lazdins, F. Aboul-ela, G. Varani, J. Karn and T. Klimkait, Proc. Natl. Acad. Sci. U. S. A., 1997, 94, 3548-3553.

235 L. P. Labuda, A. Pushechnikov and M. D. Disney, ACS Chem. Biol., 2009, 4, 299-307.

236 Y. U. Kwon and T. Kodadek, J. Am. Chem. Soc., 2007, 129, 1508-1509.

237 J. Schwochert, R. Turner, M. Thang, R. F. Berkeley, A. R. Ponkey, K. M. Rodriguez, S. S. F. Leung, B. Khunte, G. Goetz, C. Limberakis, A. S. Kalgutkar, H. Eng, M. J. Shapiro, A. M. Mathiowetz, D. A. Price, S. Liras, M. P. Jacobson and R. S. Lokey, Org. Lett., 2015, 17, 2928-2931.

238 W. Huang, J. Seo, J. S. Lin and A. E. Barron, Mol. BioSyst., 2012, 8, 2626-26288.

239 S. B. L. Vollrath, D. Fürniss, U. Schepers and S. Bräse, Org. Biomol. Chem., 2013, 11, 8197-8201.

240 M.-K. Shin, Y.-J. Hyun, J. H. Lee and H.-S. Lim, ACS Comb. Sci., 2018, 20, 237-242.

241 H.-S. Kim, Y. Lee, M. H. Shin and H.-S. Lim, Chem. Commun., 2021, 57, 6800-6803.

242 E. F. Haney, S. C. Mansour and R. E. W. Hancock, in Antimicrobial Peptides: Methods and Protocols, ed. P. R. Hansen, Springer New York, New York, NY, 2017, DOI: 10.1007/978-1-4939-6737-7_1, pp. 3-22.

243 B. Goodson, A. Ehrhardt, S. Ng, J. Nuss, K. Johnson, M. Giedlin, R. Yamamoto, W. H. Moos, A. Krebber, M. Ladner, M. B. Giacona, C. Vitt and J. Winter, Antimicrob. Agents Chemother., 1999, 43, 1429-1434.

244 S. Ng, B. Goodson, A. Ehrhardt, W. H. Moos, M. Siani and J. Winter, Bioorg. Med. Chem., 1999, 7, 1781-1785.

245 J. A. Patch and A. E. Barron, J. Am. Chem. Soc., 2003, 125, 12092-12093.

246 J. S. Khara, B. Mojsoska, D. Mukherjee, P. R. Langford, B. D. Robertson, H. Jenssen, P. L. R. Ee and S. M. Newton, Front. Microbiol., 2020, 11, 417.

247 R. M. Green and K. L. Bicker, Int. J. Antimicrob. Agents, 2020, 56, 106048.

248 N. P. Chongsiriwatana, T. M. Miller, M. Wetzler, S. Vakulenko, A. J. Karlsson, S. P. Palecek, S. Mobashery and A. E. Barron, Antimicrob. Agents Chemother., 2011, 55, 417-420.

249 T. S. Ryge and P. R. Hansen, J. Pept. Sci., 2005, 11, 727-734.

250 T. S. Ryge and P. R. Hansen, Bioorg. Med. Chem., 2006, 14, 4444-4451.

251 T. S. Ryge, N. Frimodt-Møller and P. R. Hansen, Chemotherapy, 2008, 54, 152-156.

252 H. L. Bolt, G. A. Eggimann, C. A. B. Jahoda, R. N. Zuckermann, G. J. Sharples and S. L. Cobb, MedChemComm, 2017, 8, 886-896.

253 N. Molchanova, P. R. Hansen, P. Damborg, H. M. Nielsen and H. Franzyk, ChemMedChem, 2017, 12, 312-318.

254 N. Molchanova, J. E. Nielsen, K. B. Sørensen, B. K. Prabhala, P. R. Hansen, R. Lund, A. E. Barron and H. Jenssen, Sci. Rep., 2020, 10, 14805.

255 J. A. Turkett and K. L. Bicker, ACS Comb. Sci., 2017, 19, 229-233.

256 N. Frederiksen, P. R. Hansen, D. Zabicka, M. Tomczak, M. Urbas, I. Domraceva, F. Björkling and H. Franzyk, ChemMedChem, 2020, 15, 2544-2561.

257 N. Frederiksen, P. R. Hansen, F. Björkling and H. Franzyk, Molecules, 2019, 24, 4429.

258 M. Vestergaard, B. Skive, I. Domraceva, H. Ingmer and H. Franzyk, Int. J. Mol. Sci., 2021, 22, 5617.

259 G. Diamond, N. Molchanova, C. Herlan, J. A. Fortkort, J. S. Lin, E. Figgins, N. Bopp, L. K. Ryan, D. Chung, R. S. Adcock, M. Sherman and A. E. Barron, Pharmaceuticals, 2021, 14, 304.

260 H. Sung, J. Ferlay, R. L. Siegel, M. Laversanne, I. Soerjomataram, A. Jemal and F. Bray, CA Cancer J. Clin., 2021, 71, 209-249.

261 A. Bhowmik, M. Basu and M. K. Ghosh, Front. Biosci., 2017, 9, 101-108.

262 C. Mas-Moruno, L. J. Cruz, P. Mora, A. Francesch, A. Messeguer, E. Pérez-Paya and F. Albericio, J. Med. Chem., 2007, 50, 2443-2449.

263 W. Huang, J. Seo, S. B. Willingham, A. M. Czyzewski, M. L. Gonzalgo, I. L. Weissman and A. E. Barron, PLoS One, 2014, 9, e90397.

264 J. Lee, W. Huang, J. M. Broering, A. E. Barron and J. Seo, Bioorg. Med. Chem. Lett., 2015, 25, 2849-2852. 
265 N. Reßing, V. Marquardt, C. G. W. Gertzen, A. Schöler, A. Schramm, T. Kurz, H. Gohlke, A. Aigner, M. Remke and F. K. Hansen, MedChemComm, 2019, 10, 1109-1115.

266 G. A. Eggimann, H. L. Bolt, P. W. Denny and S. L. Cobb, ChemMedChem, 2015, 10, 233-237.
267 M. Montolio, J. Messeguer, I. Masip, P. Guijarro, R. Gavin, J. Antonio Del Río, A. Messeguer and E. Soriano, Chem. Biol., 2009, 16, 691-701. 268 M. Corredor, R. Bonet, A. Moure, C. Domingo, J. Bujons, I. Alfonso, Y. Pérez and À. Messeguer, Biophys. J., 2016, 110, 1291-1303.

269 T. Kodadek, Chem. Biol., 2014, 21, 1066-1074. 